\title{
Adipose-Derived Stem Cells in Bone Tissue Engineering: Useful Tools with New Applications
}

\author{
Gabriele Storti $\mathbb{D}^{1},{ }^{1}$ Maria Giovanna Scioli, ${ }^{2}$ Bong-Sung Kim, ${ }^{3}$ Augusto Orlandi $\mathbb{D},{ }^{2}$ \\ and Valerio Cervelli ${ }^{1}$ \\ ${ }^{1}$ Plastic and Reconstructive Surgery, Department of Surgical Sciences, University of Rome - "Tor Vergata", Italy \\ ${ }^{2}$ Anatomy Pathology Institute, Department of Biomedicine and Prevention, University of Rome - "Tor Vergata", Italy \\ ${ }^{3}$ Division of Plastic Surgery and Hand Surgery, University Hospital Zurich, Switzerland
}

Correspondence should be addressed to Gabriele Storti; gabriele.stortimd@gmail.com

Received 23 August 2019; Accepted 9 October 2019; Published 6 November 2019

Guest Editor: Francesco De Francesco

Copyright ( 2019 Gabriele Storti et al. This is an open access article distributed under the Creative Commons Attribution License, which permits unrestricted use, distribution, and reproduction in any medium, provided the original work is properly cited.

\begin{abstract}
Adipose stem cells (ASCs) are a crucial element in bone tissue engineering (BTE). They are easy to harvest and isolate, and they are available in significative quantities, thus offering a feasible and valid alternative to other sources of mesenchymal stem cells (MSCs), like bone marrow. Together with an advantageous proliferative and differentiative profile, they also offer a high paracrine activity through the secretion of several bioactive molecules (such as growth factors and miRNAs) via a sustained exosomal release which can exert efficient conditioning on the surrounding microenvironment. BTE relies on three key elements: (1) scaffold, (2) osteoprogenitor cells, and (3) bioactive factors. These elements have been thoroughly investigated over the years. The use of ASCs has offered significative new advancements in the efficacy of each of these elements. Notably, the phenotypic study of ASCs allowed discovering cell subpopulations, which have enhanced osteogenic and vasculogenic capacity. ASCs favored a better vascularization and integration of the scaffolds, while improvements in scaffolds' materials and design tried to exploit the osteogenic features of ASCs, thus reducing the need for external bioactive factors. At the same time, ASCs proved to be an incredible source of bioactive, proosteogenic factors that are released through their abundant exosome secretion. ASC exosomes can exert significant paracrine effects in the surroundings, even in the absence of the primary cells. These paracrine signals recruit progenitor cells from the host tissues and enhance regeneration. In this review, we will focus on the recent discoveries which have involved the use of ASCs in BTE. In particular, we are going to analyze the different ASCs' subpopulations, the interaction between ASCs and scaffolds, and the bioactive factors which are secreted by ASCs or can induce their osteogenic commitment. All these advancements are ultimately intended for a faster translational and clinical application of BTE.
\end{abstract}

\section{Introduction}

Bone is a complex tissue and participates into several physiological processes, including body movements, mineral (calcium and phosphate) homeostasis and storage, endocrine functions, and, in the bone marrow, hematopoiesis $[1,2]$. Bone fractures are among the most frequent organ injuries, and high energy traumas can ultimately result in complex fracture or losses of bone tissue. Additionally, oncological skeletal surgery, malformations, prosthesis revision, or osteomyelitis can determine segmental loss of osseous structures. Usually, bone tissues present an excellent self-repair and regeneration capacity through the recruitment of osteopro- genitor cells from the surroundings, which entails scarless healing as the outcome [3]. Unfortunately, sometimes the damage exceeds bone self-healing capacity ultimately leading to delayed healing, scar formation, and nonunion or persistent bone defects, in the worst scenario [4]. Usually, a scarce or compromised vascularization and a reduced number of progenitor cells underlie these conditions, possibly worsened by patients' comorbidities, lifestyle, or genetic factors [5].

Hitherto, the gold standard to treat these conditions is an autologous bone graft, which is highly biocompatible and has a low risk for rejection. Nonetheless, many drawbacks could hinder good results for autograft, including their limited accessibility, a limited amount of material available, 
and morbidity at the donor site $[6,7]$. To overcome these limitations, bone tissue engineering (BTE) is aimed at recreating bone substitutes that are readily available, highly biocompatible, and with a significant regenerative potential [8]. Isolation and characterization of progenitor cells for therapeutic use have significantly improved the possibilities of BTE [9]. Among staminal elements, mesenchymal stem cells (MSCs), first isolated from bone marrow, offered convenient features since they are obtained from adult patients and have the ability to undergo osteogenic differentiation [10]. More recently, adipose tissue emerged as an optimal source of MSCs [11]. Adipose stem cells (ASCs) exhibit several advantages, even in comparison to bone marrow MSCs. They are easy to harvest and to isolate; they have a high proliferative capacity and differentiative capacity, both toward angiogenic and osteogenic lineages [12].

Although the first successful experiences of BTE using ASCs date back to more than ten years ago $[13,14]$, a better understanding of different ASC subpopulations, their physiology, differentiative mechanisms, and paracrine actions has allowed a continuous development of new applications for ASC use in designing tissue engineering products (TEPs) [15]. Usually, TEPs combine three factors: (1) scaffold, (2) osteoprogenitor cells, and (3) bioactive factors. The maximization of the osteogenic potential of ASCs led to the development of novel scaffolds. Concurrently, subpopulations of ASCs with an enhanced capacity to induce bone formation have been isolated. The paracrine role of ASCs has also been studied further. On this behalf, ASCs, as an essential source of bioactive factors, can have a high impact also on tissues of the recipient site. In particular, ASC-derived exosomes and microRNAs (miRNAs) have shown significant osteoinductive capacities, thus being another mechanism for ASC-promoted bone formation. In this review, we are going to discuss recent discoveries involving ASC use in tissue engineering, focusing on their role and interactions with the other components of TEPs.

\section{Adipose Stem Cells (ASCs) and Their Subpopulations}

Among MSCs, ASCs present some advantages for tissue engineering applications. Adipose tissue is easy to harvest and contains a higher number of staminal precursors, up to 2,500-fold higher than in bone tissue [16]. However, ASCs share several features with other MSCs, which are defined by a position statement of the International Society for Cellular Therapy (ISCT). Three minimal criteria define cultured MSCs: (i) plastic adherence in standard culture conditions; (ii) positivity for the expression of CD105, CD73, and CD90 and negativity for CD45, CD34, CD14 or CD11b, $\mathrm{CD} 79 \alpha$ or CD19, and HLA-DR surface molecules; and (iii) potential to undergo trilineage differentiation (adipogenic, chondrogenic, and osteogenic) [17]. Nonetheless, it has emerged over time that, among ASCs, different subpopulations could be identified. ASCs are part of the perivascular niche, but the lack of expression of CD31 distinguishes them from endothelial cells that are positive for it [18].
CD146, an adhesion molecule also known as Mel-CAM (melanoma cell adhesion molecule), has been used for the identification and purification of perivascular progenitor cells [19]. Among the perivascular ASCs, two different subpopulations could be identified using the combined analysis of different surface markers, like CD146, CD34, and CD31: (i) cells which are CD146+ CD34- CD31- also defined as pericytes and (ii) CD146- CD34+ CD31- also defined as adventitial cells [20-23]. Adventitial cells are located in an outer layer of the supra-adventitial fat, whereas pericytes are closely associated with the microvasculature [23]. They hold strict relationships with endothelial cells, and their interplay has a significant role in the regulation of angiogenesis. [24]. Some hypotheses consider pericytes as a more staminal form that undergo a differentiation process from inside outwards [25]. Both cell types share with MSC features like growth, morphology, surface markers, and clonal multilineage differentiation potential [26-29]. According to Rad et al., the buccal fat pad, compared to abdominal and hip fat, showed the highest amount of CD146-positive cells, higher proliferation rate, and expression of osteogenic and angiogenic markers [30].

Many authors investigated the osteogenic capacity of sorted CD146+ CD34- CD31- pericytes from adipose tissue and evaluated their possible use for bone tissue engineering. James et al. demonstrated for the first time the higher osteogenic capacity of sorted pericytes from human lipoaspirate, compared to matched unsorted ASCs, both in vitro and in vivo [31]. Pericytes had a better osseous differentiation compared to unsorted cells, under osteogenic conditions in vitro. CD146+ cells formed more bone than unsorted cells in vivo as well, even without predifferentiation. Pericytes confirmed a high osteogenic capacity when seeded on a cancellous bone scaffold and tested on a calvarial critical-sized defect [32]. In a rat spine fusion model, human pericytes were able to induce both intramembranous and endochondral bone formation. A complete fusion of lumbar segments was obtained in all the rats treated with pericytes and ossification, bone deposition and bone strength increased in a dose-dependent fashion [33]. Efficacy of human pericytes for bone formation was also evident in an atrophic bone nonunion animal model. An increased fracture callus size and increased mineralization after three weeks finally resulted in increased bone union [34]. Interestingly, in all these xenografts models, aside from the osteogenic differentiation of human pericytes, a paracrine effect was evident, which determined a repopulation of the defect by host cells. Over time, only a little chimerism could be detected, with a limited presence of human cells. Whether the trophic/secretory effect is more critical for new bone formation than the cellular osteogenic differentiation is not clear yet [35].

Wang et al. [36] have demonstrated that cocultivation of CD146+ pericytes and patient-matched CD34+ adventitial cells resulted in a better osteogenic and vasculogenic differentiation. When evaluated on a critical-sized calvarial defect model in NOD/SCID mice, the combination of CD146+ pericytes with $\mathrm{CD} 34+$ adventitial cells determined a more efficient reossification than either cell type alone. It could be inferred that CD146+ pericytes and CD34+ adventitial 
cells display overlapping and complementary roles, even though with different functions in bone defect repair. Consequently, CD146+ pericytes and CD34+ adventitial cells may demonstrate a synergistic effect on bone healing when applied together as a combined therapy.

Therefore, according to literature data, a more precise selection and expansion of cellular subpopulations, under Good Manufacturing Practice (GMP) conditions, could ultimately lead to more efficient engineering protocols.

\section{Scaffolds and Adipose Stem Cells}

Scaffolds are three-dimensional constructs that are designed and intended to recreate the extracellular matrix (ECM), thus promoting the regeneration of a functional bone. Scaffolds should guide the healing process, promote the differentiation of progenitor cells, and mimic the extracellular environment while providing mechanical support [37].

Various scaffolds have been investigated for bone tissue engineering (BTE) and synthesized using both inorganic and organic materials [38]. Generally, an ideal scaffold should have precise features in order to have an optimal integration and provide the correct stability [39]. An ideal scaffold should be biocompatible, thus eliciting a minimal inflammatory and immunological response, and it should be biodegradable, which means that it should be substituted entirely, over time, by autologous tissue. The ability to mimic the ECM, to facilitate hydroxyapatite (HA) formation and mineral deposition, and ultimately to provide a physical structure suitable for bone growth inside and across it is defined as osteoconduction. Even though stainless steel too has been proven to be osteoconductive, biodegradable scaffolds offer the best osteoconductive properties [40]. Nonetheless, a controlled scaffold degradation is desirable in order to allow the new tissues to grow into it while the scaffold guarantees adequate mechanical support and stiffness until the process of integration ends. This necessity is particularly true in load-bearing areas [41].

Under this aspect, it is fundamental to balance carefully two properties in a scaffold: its porosity and its stiffness. The first allows an optimal vascular inosculation and cellular ingrowth, mimicking the native trabecular bone, while the second is necessary for adequate structural support, which is less in a highly porous material [39].

Porosity is a critical parameter for the interactions between cells and the scaffold. A too narrow diameter of the pores can limit the penetration throughout the scaffold of newly formed vascular structures and cell migration, while too wide pores impair the surface area available for cell adhesion [42, 43]. Both these cellular processes are critical for cell differentiation, proliferation, and migration, ultimately determining an optimal integration of the scaffold and its suitability for BTE [44]. Therefore, optimization of pore size is fundamental during scaffold construction [45].

As mentioned above, osteoconductive scaffolds exert their properties passively and act as relatively inert support that guides bone ECM formation, cell migration, and proliferation toward the regeneration of the defect. Osteoconductive materials are efficacious mainly with partly differentiated cells like osteoblast and preosteoblast but do not induce osteogenic differentiation of osseous progenitor cells and mesenchymal stem cells (including ASC) [8]. On the other hand, osteoinductive biomaterials can recruit progenitor cells and stimulate their osteoblastic commitment and differentiation, which allows de novo bone formation [46, 47]. Autografts and tissue engineering products (TEPs), where scaffolds are enriched with stem cells or osteogenic factors, e.g., BMPs [48, 49], usually fall among osteoinductive materials. However, some biomaterials, like some calcium phosphate cements, have intrinsic osteoinductive features even without the addition of osteogenic factors [50, 51]. Osteoinduction, a crucial characteristic of scaffolds, has been widely exploited together with ASC and osteogenic factors in order to obtain optimal TEPs. Alongside with excellent osteoinductive properties, a full osteointegration of the scaffold into the host bone relies also on adequate vascular support. Neoangiogenesis into the graft should allow connections to the host microvasculature. A stable vascularization of the graft and a vascular supply to the central part of the graft can hold its bioactive function and avoid necrosis, which is a significant risk to be considered especially in large bone grafts $[52,53]$. The capacity of a biomaterial to host vascular ingrowth is named angioconduction, whereas the ability of a biomaterial to actively stimulate and promote the formation of new vessels goes under the name of angioinduction [39]. Osteoinduction and osteoconduction, angioinduction and angioconduction together with biocompatibility, biodegradability, and physical and mechanical properties of the scaffold are crucial in order to obtain ideal TEPs for bone reconstruction.

ASCs have been employed for bone reconstruction together with several scaffold types derived both from inorganic and organic sources. Several materials have been investigated for scaffold production, ranging from decellularized tissue matrices to inorganic ceramics (e.g., hydroxyapatite (HA), coralline-derived hydroxyapatite (cHA), tricalcium phosphate (TCP), calcium sulphates, glass ceramics, calcium phosphate-based cements, and bioglass), synthetic biodegradable polymers such as polylactic acid (PLA) and polyglycolic acid (PGA), or combinations of two or more of them [54].

ASCs have been tested on several biomimetic scaffolds in order to obtain an optimal osteogenic differentiation and ultimately an ideal TEP for bone reconstruction. The capacity of a scaffold to directly induce osteogenic differentiation of ASCs, without bioactive factors, could help in simplifying the approach to bone reconstruction in the future. Table 1 provides a synthetic overview of recent literature about the combination of scaffolds and ASCs for bone tissue engineering.

3.1. Decellularized Matrices. Scaffolds derived from acellular matrices have several advantages. They have a structure similar to that of the original bone extracellular matrix; they can recapitulate the complex microenvironment of naïve bone, and they have shown significative osteoinductive capacities [74]. These materials require a donor tissue and present the possible risk of transmission of infectious diseases as the main drawback [75]. 


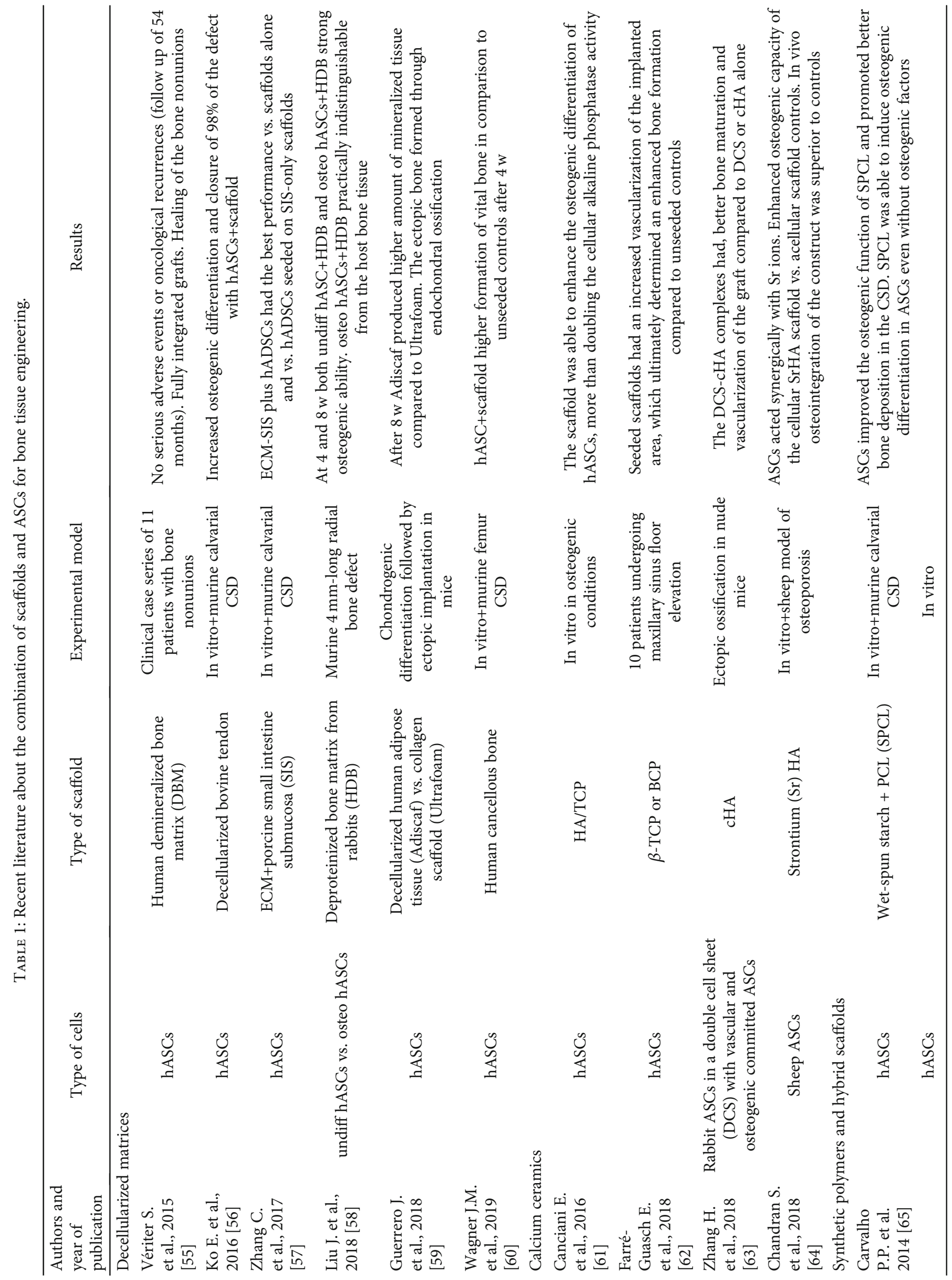




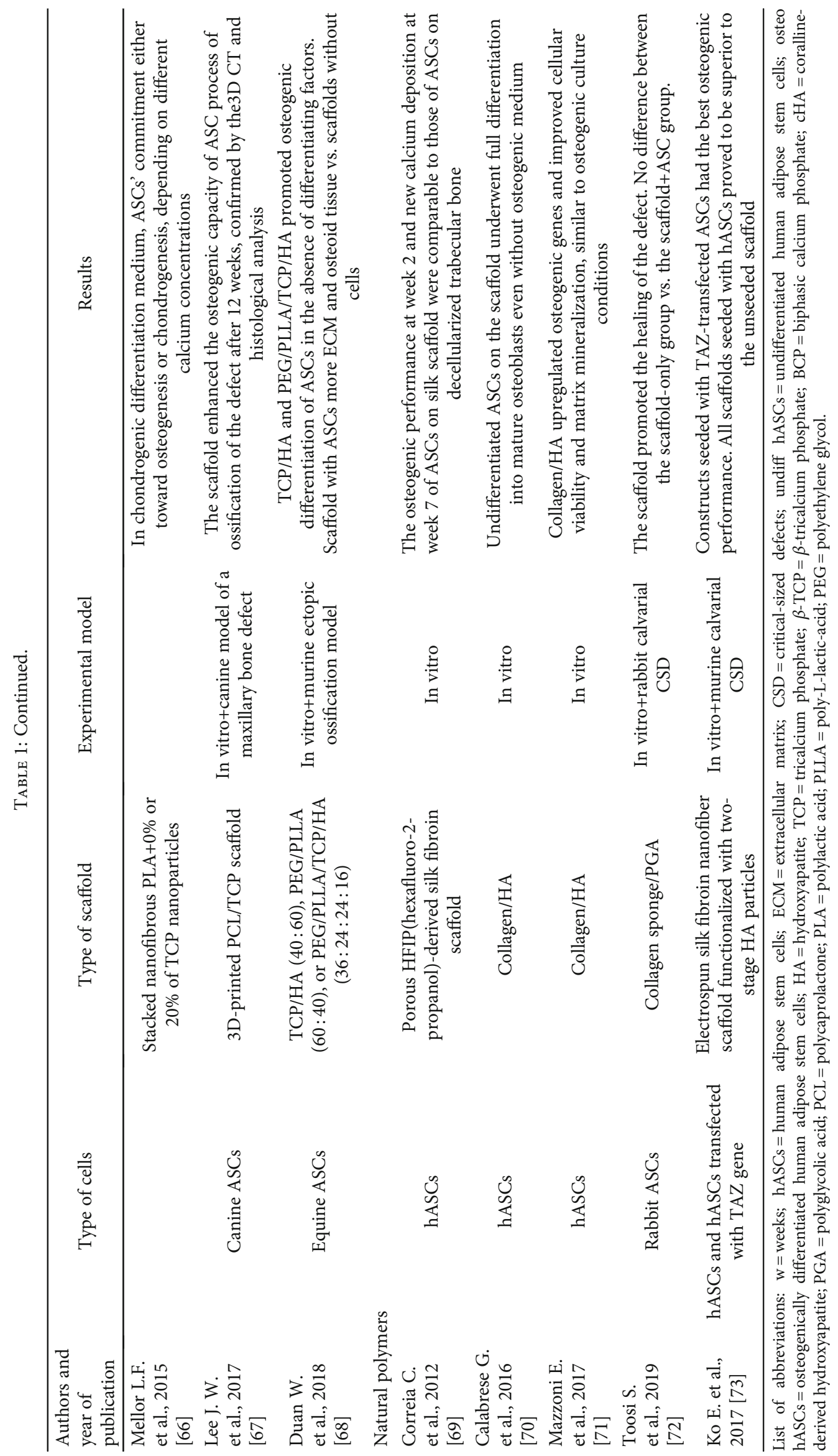


ASCs have been used together with acellular matrices from different sources. Allografts and xenografts have been derived mainly from bone tissue $[55,58,60,76,77]$ but also from small intestine submucosa [57] or from adipose tissue [59].

Ko et al. tested a nanostructured tendon-derived scaffold on a mouse model of calvarial critical-sized bone defects together with human ASCs (hASCs). hASCs seeded on this nanostructured tendon-derived scaffold had an enhanced focal adhesion and an increased osteogenic differentiation after 21 days. The same construct was layered on the mouse calvarial defects, ultimately obtaining well-vascularized bone tissue and a defect closure in 8 weeks [56].

Liu et al. [58] combined hADSC with a deproteinized bone matrix, derived from New Zealand rabbits. The heterogeneous deproteinized bone (HDB) has no severe immunogenicity, and it holds a natural porosity adequate for cell adhesion proliferation and differentiation [78]. Composites with HDB were obtained both with naïve hASCs and with hADSC which have already undergone a partial osteogenic differentiation. The constructs were tested on a murine $4 \mathrm{~mm}$-long radial bone defect. Both types of HDB-ASC composites showed a strong osteogenic ability when compared to control groups, at four and eight weeks. The best performance was obtained by the HDBASC constructs combined with osteogenic ASCs which filled the bone defect area and were practically indistinguishable from the host bone tissue.

Porcine small intestine submucosa (SIS) was also investigated as another option for bone tissue engineering in a mouse calvarial defect model [57]. The SIS scaffold was initially seeded with osteoblasts from the MC3T3-E1 cellular line in order to obtain ECM deposition. After four weeks, the ECM-SIS scaffold was decellularized. hASCs seeded on the ECM-SIS scaffold underwent osteogenic differentiation even in the absence of the osteogenic differentiation medium. They were significantly more efficient in bone tissue formation when compared to those seeded in the SIS-only scaffold. The murine model confirmed these in vitro data. In mice, constructs made of ECM-SIS plus hADSCs had the best performance in comparison to scaffolds alone and also to ADSCs seeded on SIS-only scaffolds.

Among human allogenic materials, Wagner et al. [60] tested a construct made of decellularized human cancellous bone seeded with hASCs, both in vitro and in a murine femur model with a critical-sized defect. The scaffold was able to increase the osteogenic differentiation of hASCs when compared to controls. In the murine model, after four weeks, seeded scaffolds showed a significative higher formation of vital bone in comparison to unseeded controls Moreover, the scaffold showed optimal osteoconductive properties and favored both the differentiation of hASCs into CD31+ endothelial cells and an increased neoangiogenesis.

In a study by Vériter et al. [55], an ASC-based product was created combining ASCs and human demineralized bone matrix (DBM) which has powerful osteoinductive properties.

ASCs at passage four were incubated with an osteogenic differentiation medium for 15 to 18 days and then added to
DBM. These grafts were implanted on 11 patients with bone nonunion from different etiologies, including postoncological reconstructions and congenital defects. No serious adverse events or oncological recurrences were reported during the follow-up of 54 months. The grafts were fully integrated, determining the healing of the bone nonunions.

Adipose tissue was also reported as a potential candidate for a scaffold intended for bone reconstruction. Guerrero et al. [59] cultivated human adipose tissue from liposuction for three weeks in a proliferation medium on agarose-coated plates in order to obtain a construct called Adiscaf. Adiscaf was confronted with a collagen scaffold (Ultrafoam) seeded with a monolayer of ASCs from the same patient. Both Adiscaf and the collagen construct were held for four weeks in a chondrogenic differentiation medium. Adiscaf differentiated into cartilage tissue with the synthesis of glycosaminoglycans and type II collagen. When implanted into a subcutaneous pouch on nude mice, the cartilage tissue formed into the Adiscaf was able, after eight weeks, to produce a higher amount of mineralized tissue compared to Ultrafoam-based constructs. The ectopic bone formed through endochondral ossification, and Adiscaf was superior to Ultrafoam both in vitro and in vivo, thus being a possible candidate for the generation of osteogenic grafts for bone repair.

3.2. Ceramics. Several synthetic materials, derived both from inorganic and organic origins, have been tested together with ASCs as scaffolds for bone tissue engineering.

Calcium phosphate ceramics (e.g., hydroxyapatite (HA), coralline-derived hydroxyapatite (cHA), tricalcium phosphate (TCP), calcium sulfates, glass ceramics, calcium phosphate-based cements, and bioglass) have been introduced about 40 years ago as bone substitutes [54, 79]. They have excellent osteoinductive properties [80,81], and they have been used alone to treat distal radial fracture [82, 83], but they have the relative disadvantage of a high brittleness, TCP in particular [84]. Therefore, it could be problematic to use ceramics, especially when a construct for loadbearing areas is needed [85]. The combination of calcium ceramics together (e.g., HA and TCP) or mineral substitution with strontium or magnesium can improve their mechanical properties, their biodegradability, and their osteoinductive capacity [86]. The association of $\beta$-TCP and HA has better mechanical properties than $\beta$-TCP alone, while it also enables a faster and higher bone ingrowth rate than using HA alone [87].

It was demonstrated that the extracellular calcium concentration could influence the differentiation of ASCs toward an osteogenic phenotype also without any other soluble osteogenic factor [88]. Elevated calcium induced osteogenesis and inhibited chondrogenesis in hASC even in the presence of the chondrogenic differentiation medium. This phenomenon could be an explanation for the osteoinductive and osteoconductive capacities of calcium phosphate ceramics like tricalcium phosphate (TCP) [66]. Interestingly, based on these observations, Mellor et al. developed a stacked polylactic acid (PLA) nanofibrous scaffolds containing either $0 \%$ or $20 \%$ tricalcium phosphate (TCP) nanoparticles. In chondrogenic differentiation mediums, 
different extracellular calcium concentrations, in different layers of the scaffold, determined ASCs' commitment either toward osteogenesis or into chondrogenesis, thus exploiting the different calcium concentrations for site-specific differentiation.

In an in vitro model, an HA/TCP scaffold was able to enhance the osteogenic differentiation of hASCs, more than doubling the cellular alkaline phosphatase activity when added to the osteogenic differentiation medium [61].

$\beta$-TCP with ASCs was tested in several clinical settings, particularly in maxillofacial surgery and neurosurgery, with excellent results in terms of ossification [62, 89-91].

In a phase I study by Farré-Guasch et al. [62], ten patients undergoing maxillary sinus floor elevation (MSFE) for dental implant placement were divided into two groups. Each group received in a single-step procedure autologous stromal vascular fraction (SVF), containing ASCs, mixed either with $\beta$ TCP or with biphasic calcium phosphate (BCP), consisting of $60 \%$ hydroxyapatite (HA) and $40 \% \beta$-tricalcium phosphate $(\beta$-TCP). A control group was treated with ceramics only. Both the study groups, compared to the control group, had an increased vascularization of the implanted area, which ultimately determined an enhanced bone formation.

cHA was tested by a Chinese group for the construction of a vascularized tissue-engineered bone together with a double-cell sheet complex [63]. A double-cell sheet (DCS) was created inducing ASCs toward vascular and osteogenic commitment at the same time. The DCS was engineered with cHA, using different patterns. The pattern organized with endothelial cell sheets covered with osteogenic cell sheets had the best results. Moreover, the DCS-cHA complexes had, in general, better bone maturation and vascularization of the graft compared to DCS or cHA alone, when implanted in nude mice and tested for ectopic ossification.

As mentioned above, incorporating minerals, like the strontium ( $\mathrm{Sr}$ ), into ceramics like HA, could enhance the osteoinductive properties of the inorganic cements. Sr ions have the ability to regulate osteoclast activity [92] and to improve the osteointegration when incorporated into bioactive scaffolds [93] or together with HA [94]. ASCs engineered in a strontium hydroxyapatite (SrHA) scaffold were used as a tissue-engineered construct (cSrHA) on a sheep model of osteoporosis [64]. ASCs demonstrated to act synergically with $\mathrm{Sr}$ ions, thus enhancing the osteogenic capacity of the SrHA scaffold when compared to acellular scaffold controls. ASCs adhered and proliferated on the SrHA scaffold, retaining an optimal osteogenic capacity in vitro. In the in vivo model, the osteointegration of the construct was superior to controls.

3.3. Synthetic Polymers and Hybrid Scaffolds. Synthetic polymers have been extensively investigated because of many advantages that they could offer for scaffold design, including biocompatibility, controllable biodegradability, and their physio/chemical properties. Polylactic acid (PLA), polyglycolic acid (PGA), polycaprolactone (PCL), and the copolymer poly(lactic acid-co-glycolic acid) (PLGA) are among the most frequently tested for bone tissue engineering [95]. ASCs have been combined with synthetic polymers with excellent support to osteogenic differentiation in several preclinical models [1, 96-98]. Synthetic polymers offer advantageous chemical, biological, and flexible mechanical properties. They are highly pure, readily reproducible, and easy to be tailored to fulfill specific needs. Nonetheless, synthetic polymers have several drawbacks when used alone. They have a fast degradation rate and a reduced compressive modulus, and they lack osteoinductive capacity, even though PCL has shown the ability to increase the osteogenic differentiation of various human tissue-derived mesenchymal stem cells (including ASCs) through the activation of the $\mathrm{Wnt} / \beta$ catenin and Smad3 signaling pathways [99]. Moreover, some synthetic polymers, such as PLGA and poly-L-lactic acid (PLLA), degrade into nonbiocompatible products, often acids, which can lead to cell dysfunction or death, via perturbation of the scaffold microenvironment. An increased acidity of the tissue microenvironment, determined by high concentrations of these degradation products, could also result in adverse responses, such as inflammation or fibrous encapsulation $[100,101]$. For the sake of overcoming their drawbacks, synthetic polymers have been often used over the years in combination with other materials like ceramics (e.g., HA or TCP), collagen, or natural polymers into hybrid scaffolds [75]. Hybridization with other materials allows synthetic polymers to increase their resistance to compression and their osteoinductive capacity and to prolong their degradation time. At the same time, the high versatility provided by synthetic polymers allows using these materials for scaffold creation through several bioengineering techniques like 3D bioprinting or electrospinning [37, 102]. Furthermore, synthetic polymers (e.g., PLGA) can be used for encapsulation and progressive release of bioactive molecules, exploiting the biodegradability profile of the materials [103-105].

Lee et al. [67] tested a 3D-printed PCL/TCP scaffold seeded with ASCs on a canine model of a maxillary bone defect. This scaffold enhanced the osteogenic capacity of ASCs as it was demonstrated by RT-PCR and Western blot analysis for COL1, OCN, and RUNX2. Moreover, 3D CT scans demonstrated a process of ossification of the defect after 12 weeks, confirmed by the histological analysis.

ASCs were able to undergo direct osteogenic differentiation induced by different polymer-mineral constructs in a murine model. In a study by Duan et al. [68], the different scaffolds, made of synthetic polymers mixed with different ceramics, were able to promote osteogenic differentiation of ASCs in the absence of differentiating factors. Scaffold seeded with ASCs displayed more ECM and osteoid tissue compared to those scaffolds without cells.

The addition of starch to PCL (SPCL) was used to create a wet-spun SPCL scaffold which proved to be biodegradable and biocompatible and able to harbor undifferentiated hASCs and support their proliferation and osteogenic differentiation [65]. Starch increased the resistance to tensile forces of PCL, thus improving its mechanical properties. A construct made of undifferentiated hASCs and the SPCL scaffold was tested on a murine calvarial defect model. ASCs improved the osteogenic function of SPCL and promoted significantly better bone deposition. SPCL was able to induce osteogenic differentiation in ASCs even without the addition of osteogenic 
factors, and the newly formed tissue was well integrated into the surrounding tissues.

3.4. Natural Polymers. Natural polymers are derived from various sources, mainly animals and plants [106]. They were among the first scaffolds to be studied in combination with hASCs to design TEPs because of their properties close to those of the ECM [107-111]. Natural polymers combined with hASCs for the use in bone tissue engineering applications are often animal derivatives. However, polysaccharides too like chitosan $[112-114]$ or cornstarch $[65,115]$ have been investigated for this purpose. In between the animal-derived polymers, ASCs have demonstrated to positively interact mainly with fibrin [116], collagen [117, 118], gelatin [111, $119,120]$, and silk $[69,121,122]$, through the recognition of specific domains present in polymers' structures. These polymers have a good biodegradability profile, and they can be degraded, modified, or adsorbed by the action of naturally occurring enzymes [123]. Since they are versatile, they are often used in combination with other scaffolding materials (e.g., ceramics or synthetic polymers), resulting in new constructs that incorporate their biodegradability and their biological properties, which mimic those of the ECM but have superior mechanical characteristics [124]. These composite constructs are easy to use and to adapt to multiple tissue engineering techniques like phase separation, electrospinning, or 3D printing [125-129].

When seeded on composite scaffolds synthesized with natural polymers, ASCs proved optimal adhesion, proliferation, and osteogenic differentiation, in many cases without the use of differentiating agents, both in vivo and in vitro.

The combined use of collagen and HA proved optimal osteoinductive and osteoconductive properties both in vitro and in vivo [70,71, 130,131].

Mazzoni et al. [71] proved that the collagen/HA is an ideal microenvironment for hASC adhesion and proliferation, and it determines an upregulation of osteogenic genes and an improvement of cellular viability and matrix mineralization, similar to that obtained under osteogenic culture conditions.

It has been demonstrated that collagen and HA scaffolds activate distinct osteogenesis signaling pathways in ASCs [130]. Collagen seemed to stimulate ECM deposition and osteoblastic differentiation through the stimulation of the extracellular signal-regulated protein kinase (ERK) pathway, whereas HA stimulated the osteogenic differentiation of ASCs via the $\mathrm{Wnt} / \beta$-catenin pathways which determined an increase in the osteoprotegerin (OPG)/receptor activator of nuclear factor-kappa $\beta$ ligand (RANKL) ratio. The upregulation of these two pathways could explain the synergistic effects of collagen and HA on the osteogenic differentiation of ASCs.

Calabrese et al. [70] tested the biocompatibility and the osteogenic capacity of hASCs on collagen-HA scaffolds in vitro. Undifferentiated ASCs were able to undergo full differentiation into mature osteoblasts even without the addition of an osteogenic medium, thus demonstrating a per se osteoinductive capacity of the scaffold, which could be exploited in order to have more straightforward translational applications in the future.
Collagen has also been used together with synthetic polymers like PGA. ASCs were seeded in combination with a construct made of collagen sponge and PGA on a rabbit critical-sized calvarial bone defect [72]. In this animal model, the scaffold itself was able to promote the healing of the defect and no difference was noted in between the scaffoldonly group and the scaffold+ASC group.

Silk fibroin is a valuable alternative to other natural polymers for TEPs in combination with ASCs. It presents several advantages: in its spongeous form, it has a high mechanical and tensile strength and it has a high porosity with the possibility of different pore sizes, which eases cell attachment, proliferation, and the development of a supportive vascular network. It was demonstrated that a pore dimension of $400-600 \mu \mathrm{m}$ determines the best bone tissue formation outcomes, as evidenced by the enhanced production of bone protein (osteopontin, collagen type I, and bone sialoprotein) and calcium deposition, and the increased total bone volume, in a porous HFIP-derived silk fibroin scaffold seeded with hASCs. In an osteogenic differentiation medium, the osteogenic performance in term of alkaline phosphatase activity (AP) at week 2 and new calcium deposition at week 7 was comparable to those of cells cultured on a decellularized trabecular bone [69].

A Korean group used electrospun silk fibroin nanofiber scaffolds, which were functionalized with two-stage HA particles. HA particles were immobilized via polydopaminemediated adhesive chemistry. ASCs' interactions with this construct were tested both in vitro (under standard and osteogenic culture conditions) and in vivo, on a murine criticalsized calvarial bone defect model [56]. Furthermore, they also tested hASCs transfected with the TAZ gene. TAZ is a transcriptional modulator that triggers the osteogenic differentiation of ASCs. Constructs seeded with TAZ-transfected ASCs had the best osteogenic performance both in vitro and in vivo. However, those seeded with wild-type hASCs also proved to be superior to the unseeded scaffold. This study highlighted the possible future utility of silk fibroin nanofibrous scaffolds, enriched with inorganic components and used in combination with ASCs for bone tissue engineering.

\section{Bioactive Factors}

Bioactive factors are an integrating part of bone tissue engineering strategies, and they usually have osteoinductive and angiogenic properties [102].

Several factors like growth factors (like those in the platelet-rich plasma) or the bone morphogenetic proteins (BMPs) or drugs like simvastatin or RNA products like miRNAs have demonstrated the ability to induce osteogenic differentiation and angiogenesis into ASCs and in the host tissues [132-137].

Parallelly, the paracrine action of ASCs has become more and more evident over the years and it is responsible for their therapeutic effects, together with their differentiation capacity [138]. These paracrine effects are mostly attributable to soluble factors and exosomes which control regeneration processes and the repair of damaged sites by modulating migration, proliferation, and differentiation [139]. Soluble 
factors and exosomes, with their "cargos," are promising options for bone tissue engineering, both improving ASCs' osteogenic differentiation and enhancing bone formation through a paracrine osteoinductive activity.

Several studies have recently demonstrated that ASCsderived exosomes could have biological effects close to those of the proper cellular component, in bone regeneration, as well as in neoangiogenesis and wound healing [140-142].

4.1. Growth Factors (GFs). Usually, the ECM stores many of these bioactive factors, including many growth factors (GFs), such as FGF, TGF $\beta$, BMPs, VEGF, and IGF I and II. In specific pathophysiological conditions, these GFs are released from the ECM and become available for cells [143]. When administered exogenously for therapeutic purposes, these factors have short half-lives in their natural form. Without any protection, they are readily biodegradable and their elimination through the bloodstream rapidly lowers their local concentrations. Lower concentrations reduce their efficacy into the target organs, while systemic diffusion increases the risk of adverse effects [38].

Therefore, more adequate delivery strategies should be investigated and employed in order to have stable and efficacious steady-state levels and a prolonged release over time, which mimics what actually happens under physiological conditions. Embedding bioactive factors and exosomes into scaffolds, microsphere encapsulation, and enhanced expression through gene transfection into mesenchymal cells are among the most investigated options [39, 128, 140, 144-148].

As mentioned above, efficacious strategies in bone tissue engineering rely both on an optimal ossification of the constructs and on its adequate vascularization, which allows integration and avoids total or partial necrosis of the graft. For these purposes, GFs have been extensively studied, and among them PDGF-BB, the TGF- $\beta$ family (that includes BMP proteins), FGFs, insulin-like growth factors, and VEGF. In particular, VEGF and BMP2 were considered as the principal actors in the bone repairing process, respectively, on the vascular and osteogenic side [149]. It has been demonstrated that VEGF and BMP2 act synergistically in favor of bone formation and their coadministration is more efficacious than BMP-2 alone [150]. Three BMPs have already been approved in clinics: BMP-2 (Infuse bone graft) since 2003, BMP-7 (OP1 putty) (from 2003 to 2014 when it was withdrawn), and rhPGDF-BB (Augment ${ }^{\circledR}$ bone graft), since 2015 [9]. BMP-2 has already been used in many clinical situations together with ASCs. In several case series, a construct made of hASCs, with BMP2, onto a $\beta$-TCP scaffold, proved efficacious for the reconstruction of large maxillary or mandibular defects and those of craniomaxillofacial hard tissues in general [91, 151, 152]. Parallelly, resorbable scaffolds seeded with hASCs combined with BMP2 were used to reconstruct large craniofacial bony defects in 20 patients [90].

Many GFs useful in bone regeneration, such as b-FGF or FGF-2, IGF-1, PDGF-BB, and VEGF, are contained in significative quantities into the platelet-rich plasma (PRP) [153]. PRP can be used to induce the osteogenic differentiation of ASCs, both in vitro and in vivo [132, 154]. Several authors incorporated PRP into different types of scaffold in order to have a controlled and prolonged release of GFs and to favor ASC-mediated bone formation [155-158]. These systems allowed an increased osteogenic capacity of ASCs and an enhanced bone deposition, both in vitro and in animal models.

However, ASCs are not only the target of GFs, but they are also able to produce and secrete them in both an autocrine and paracrine way. They release microvesicles (MVs) containing angiogenic factors like FGF2, PDGF, VEGF, MMP2, and MMP9 and osteogenic molecules, such as BMP2 $[159,160]$. Furthermore, ASCs can be engineered to express and release osteogenic factors like BMP-2. Using this method, Lin et al. were able to significantly increase calvarial healing through the BMP2-expressing ASCs/gelatin constructs and highlighted the importance of combinations of growth factors and scaffold in healing pathways and their efficacy together [161].

4.2. Exosomes and miRNAs. Exosomes are extracellular vesicles with a spheroidal/discoid shape which have a diameter in between 30 and $150 \mathrm{~nm}$. They play a pivotal role in intercellular communication since they show the ability to transport specific molecules like proteins, lipids, DNAs, and RNAs from cell to cell $[162,163]$. The precise mechanisms through which exosomes determine the osteogenic differentiation of ASCs is still under debate. It has been discovered that exosomes could regulate the functions of target cells through epigenetic changes, thus determining the promotion of bone tissue repair and also their fate through the induction of proliferation or apoptosis. In these processes, mainly proteins and RNAs are involved with significant roles [164-166].

Exosomes derived from MSCs in general, and in particular those from ASCs, have been investigated in the last years as a possible strategy for osteogenic differentiation, to employ as an alternative to osteogenic differentiation mediums, GFs, and genetic modification [140, 167, 168].

Li et al. [140] tested the efficacy of exosomes derived from osteogenically committed ASCs in promoting the osteogenic differentiation of bone marrow MSCs (bmMSCs) and bone tissue formation. In order to mimic a physiological release, the exosomes were bound to a PLGA/PDA matrix, which allowed a slow and controlled release regulated by its biodegradability properties. In about 48 hours, bmMSCs almost completely internalized the exosomes that stimulated cell proliferation, migration, and osteogenic differentiation, in vitro. Moreover, the cell-free constructs made of PLGA/PDA+exosomes, implanted on a murine criticalsized calvarial bone defect, actively promoted stem cell migration, homing, and new bone formation, in a better way than the PLGA/PDA control scaffold.

In a study by Lu et al. [169], the efficacy of ASCs' exosomes was also confirmed on human primary osteoblastic cells (HOBs), stimulating proliferation, differentiation, and bone-forming capacity. They also demonstrated that preconditioning the ASCs with tumor necrosis factor-alpha (TNF$\alpha$ ), for three days, further increased the capacity of ASCs' exosomes to induce osteogenic differentiation. They supposed that the priming with TNF- $\alpha$ mimics the acute 
inflammatory phase following a bone injury. They demonstrated that exosomes, from TNF- $\alpha$-preconditioned ASCs, stimulated the osteogenic gene expression through the Wnt signaling pathway, which is a fundamental pathway in osteogenic differentiation $[170,171]$.

Yang et al. [172] characterized the exosomes from both osteogenically differentiated and undifferentiated ASCs. In the absence of osteogenic factors, exosomes from osteogenically differentiated cells were able to promote osteogenic differentiation in undifferentiated ASCs, whereas exosomes from undifferentiated ASCs were not. Moreover, ASCderived exosomes were internalized by target ASCs faster than by other cell types, like bone marrow MSCs (6h vs. $48 \mathrm{~h})$. According to the authors, this element could be in favor of the combined use in bone tissue engineering of ASCs with ASC-derived exosomes, which limits the loss of exosome, due to a more prolonged uptake, and ultimately leads to a more efficient promotion of bone regeneration. To explain the differences between differentiated and undifferentiated ASCs, they have furthermore analyzed the miRNAs' expression profiles of both cell types. Two hundred thirtyfour genes were differently regulated comparing osteogenic ASCs' exosomes to those of undifferentiated ASCs (201 upregulated and 33 downregulated). Most of these miRNAs were related to signaling pathways involved in the osteogenetic process, like the MAPK, the Wnt, and the TGF- $\beta$ signaling pathway. For example, the level of miR-130a-3p was significantly higher in the exosomes from osteogenic ASCs. This miRNA targets and blocks SIRT7, an antagonist on the Wnt pathway, which results ultimately upregulated $[173,174]$. The mir-130a-3p/SIRT7/Wnt axis could be a molecular mechanism behind exosomes' efficacy in the regulation of ASC osteogenic differentiation.

As aforementioned, miRNAs play an essential role in the regulation of several biological processes, including osteogenesis, both positively and negatively.

Apart from those contained in ASCs' exosomes, miRNAs can be added into tissue-engineered constructs via different methods in order to improve the osteogenic efficacy of ASCs. miRNAs can be included in the structure of the scaffold which regulates their release, or they can be transfected through viral vectors into ASCs. Viral transfection carries with it, of course, some safety issues, which should be further evaluated, concerning the future translation into clinical practice [146]. An increased expression of miRNAs like miR-148b, miR-26a, miR-135, or miR-130a-3p could enhance the osteogenic processes and increment bone formation [175-179].

Rat ASCs transfected with a lentivirus expressing miR26a and seeded on an HA scaffold showed an upregulation of proosteogenic genes and an increased bone-forming capacity. This construct, transplanted in a rat tibial defect model, was able to fully close the gap in 12 weeks [180]. mir-148b proved excellent osteogenic capacity and showed a synergistic action together with BMP-2. It was tested on hASCs in multiple in vitro and in vivo models [177-179]. Two studies by Li et al. and Liao et al. transfected undifferentiated hASCS with baculoviruses coexpressing miR148 and BMP-2. mir-148b and BMP-2 were prolongedly overex- pressed, and osteogenic differentiation of ASCs was increased in both studies. Similarly, transfected hASCs seeded onto a PLGA scaffold were able to close a murine calvarial bone defect in 12 weeks.

Qureshi et al. [178] combined a truncated miR-148b mimic with photoactivated silver nanoparticles. Undifferentiated hASCs were transfected with the photoactivated miRNA148b-silver nanoparticle conjugates and seeded onto PCL scaffolds. This miRNA delivery system allows to potentially control the differentiation in vivo since miRNA conjugates remain inert until photoexposed at the appropriate dosage and wavelength. At 12 weeks, constructs made of transfected hASCs+PCL scaffold showed a statistically significant better closure of a mouse calvarial bone defect when compared to the control groups.

Conversely, other miRNAs such as miR146a, miR-17, miR-23a, and miR-31 downregulate the BMP2-induced osteogenesis, suppressing BMP-2 and several downstream factors like SMAD1/4, Runx2, and Osx. TGF $\beta 1$ upregulates the expression of these miRNAs. Therefore, antagonists of these miRNA could ultimately determine an improved bone tissue deposition [133, 175, 181]. A lentivirus expressing an antisense miR31 was transfected into rat ASCs that were tested by Deng et al. [181] on a rat critical-sized defect together with a $\beta$-TCP scaffold. The knockout of miR-31 increased the bone volume and the bone mineral density and decreased the scaffold residue in vivo, thus dramatically improving the repair of critical-sized defects at eight weeks.

Similarly, rat ASCs modified in order to express an antimiR146 were tested both in vitro and in vivo. The inhibition of miR-146 greatly enhanced ADSC-mediated bone regeneration and bone deposition in the animal model [175].

A synthetic overview of the use of bioactive factors for ASC differentiation is provided in Table 2.

\section{Conclusions}

ASCs confirmed a central role in BTE, providing many new solutions and a high versatility of application, as was evident both in vivo and in vitro. The use of ASCs for regenerative purposes has shown several advantages in comparison to other MSCs, but their interactions with the microenvironment and how these interactions affect their differentiation are still unclear. Different subpopulations of ASCs, such as pericytes and adventitial cells, have demonstrated a better performance in terms of angiogenic and osteogenic differentiation compared to unsorted ASCs. Moreover, an accurate definition of the intrinsic differentiative properties of ASCs' subpopulations could help to find the most appropriate cell for each reconstructive purpose.

New scaffolds, designed to mimic the ECM, thus creating a biological niche to harbor ASCs, are aimed to be fully biocompatible and biodegradable. They should provide adequate mechanical support and promote optimal integration into the host tissues. In this sense, scaffolds could have a strict interaction with ASCs, through the induction of their commitment toward osteogenic lineage and the controlled release of bioactive factors that enhance bone formation and vascular integration of the graft. This proactive role of 


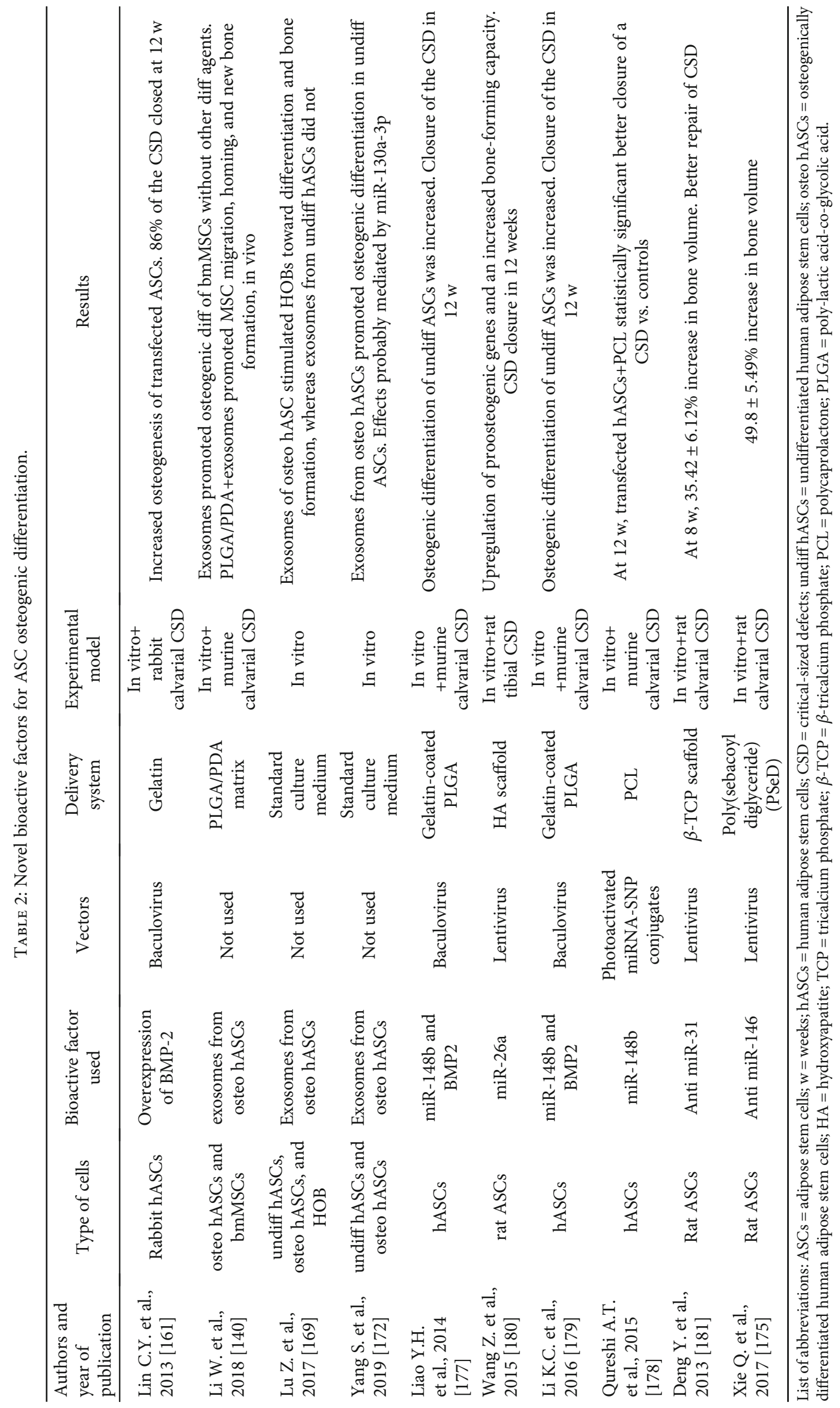


scaffolds could limit in the future the necessity for predifferentiation of ASCs, which could be committed toward the desired lineage directly in situ. At the same time, bioactive factors, released by the scaffolds, could increase the recruitment and differentiation of progenitor cells from the surroundings. In this sense, ASCs, either naïve or genetically modified, display important paracrine features. ASCs do not contribute to the defect closure via their osteogenic differentiation only. The exosomes and the miRNAs, secreted by osteodifferentiated ASCs, demonstrated to be able to induce the same processes in other cells. Therefore, ASCs are, at the same time, a target and a source of bioactive factors. Fine-tuning of all these components is needed to design constructs that are close to physiological tissues, highly integrable, widely available, and ready to use. The selection of proper elements could help in the future in simplifying the design and the use of TEPs, by reducing the necessity of strong and nonphysiological differentiative stimuli. Tailoring TEPs on specific needs would lead toward easier translational and clinical applications of bioengineering constructs, paving the way for optimal bone reconstructions.

\section{Conflicts of Interest}

The authors declare that they have no conflicts of interest.

\section{Authors' Contributions}

Gabriele Storti and Maria Giovanna Scioli equally contributed as the first authors.

\section{Acknowledgments}

Bong-Sung Kim was supported by the Deutsche Forschungsgemeinschaft (DFG) KI1973/2-1.

\section{References}

[1] J. R. Porter, A. Henson, and K. C. Popat, "Biodegradable poly( $\varepsilon$-caprolactone) nanowires for bone tissue engineering applications," Biomaterials, vol. 30, no. 5, pp. 780-788, 2009.

[2] R. Florencio-Silva, G. R. . S. Sasso, E. Sasso-Cerri, M. J. Simões, and P. S. Cerri, "Biology of bone tissue: structure, function, and factors that influence bone cells," BioMed Research International, vol. 2015, 17 pages, 2015.

[3] R. Marsell and T. A. Einhorn, "The biology of fracture healing," Injury, vol. 42, no. 6, pp. 551-555, 2011.

[4] D. Holmes, "Non-union bone fracture: a quicker fix," Nature, vol. 550, no. 7677, p. S193, 2017.

[5] D. Holmes, "Closing the gap," Nature, vol. 550, no. 7677, pp. S194-S195, 2017.

[6] M. Frohlich, W. Grayson, L. Wan, D. Marolt, M. Drobnic, and G. Vunjak-Novakovic, "Tissue engineered bone grafts: biological requirements, tissue culture and clinical relevance," Current Stem Cell Research \& Therapy, vol. 3, no. 4, pp. 254264, 2008.

[7] E. Zomorodian and M. Baghaban Eslaminejad, "Mesenchymal stem cells as a potent cell source for bone regeneration," Stem Cells International, vol. 2012, 9 pages, 2012.
[8] A. Przekora, "The summary of the most important cellbiomaterial interactions that need to be considered during _in vitro_biocompatibility testing of bone scaffolds for tissue engineering applications," Materials Science and Engineering C, vol. 97, pp. 1036-1051, 2019.

[9] A. Ho-Shui-Ling, J. Bolander, L. E. Rustom, A. W. Johnson, F. P. Luyten, and C. Picart, "Bone regeneration strategies: engineered scaffolds, bioactive molecules and stem cells current stage and future perspectives," Biomaterials, vol. 180, pp. 143-162, 2018.

[10] A. J. Friedenstein, K. V. Petrakova, A. I. Kurolesova, and G. P. Frolova, "Heterotopic of bone marrow. Analysis of precursor cells for osteogenic and hematopoietic tissues," Transplantation, vol. 6, no. 2, pp. 230-247, 1968.

[11] P. A. Zuk, M. Zhu, H. Mizuno et al., "Multilineage cells from human adipose tissue: implications for cell-based therapies," Tissue Eng., vol. 7, no. 2, pp. 211-228, 2001.

[12] F. Paduano, M. Marrelli, M. Amantea et al., "Adipose tissue as a strategic source of mesenchymal stem cells in bone regeneration: a topical review on the most promising craniomaxillofacial applications," International Journal of Molecular Sciences, vol. 18, no. 10, p. 2140, 2017.

[13] C. M. Cowan, Y. Y. Shi, O. O. Aalami et al., "Adipose-derived adult stromal cells heal critical-size mouse calvarial defects," Nature Biotechnology, vol. 22, no. 5, pp. 560-567, 2004.

[14] E. Yoon, S. Dhar, D. E. Chun, N. A. Gharibjanian, and G. R. D. Evans, "In vivo osteogenic potential of human adiposederived stem cells/poly lactide-co-glycolic acid constructs for bone regeneration in a rat critical-sized calvarial defect model," Tissue Engineering, vol. 13, no. 3, pp. 619-627, 2007.

[15] S. Kargozar, M. Mozafari, S. Hamzehlou, P. B. Milan, H. W. Kim, and F. Baino, "Bone tissue engineering using human cells: a comprehensive review on recent trends, current prospects, and recommendations," Applied Sciences, vol. 9, no. 1, p. 174, 2019.

[16] J. K. Fraser, M. Zhu, I. Wulur, and Z. Alfonso, "Adiposederived stem cells," in Methods in Molecular Biology, pp. 59-67, Humana Press, Totowa, NJ, 2008.

[17] M. Dominici, K. Le Blanc, I. Mueller et al., "Minimal criteria for defining multipotent mesenchymal stromal cells. The International Society for Cellular Therapy position statement," Cytotherapy, vol. 8, no. 4, pp. 315-317, 2006.

[18] M. Corselli, M. Crisan, I. R. Murray et al., "Identification of perivascular mesenchymal stromal/stem cells by flow cytometry," Cytometry Part A, vol. 83A, no. 8, pp. 714-720, 2013.

[19] A. W. James, P. Hindle, I. R. Murray et al., "Pericytes for the treatment of orthopedic conditions," Pharmacology \& Therapeutics, vol. 171, pp. 93-103, 2017.

[20] D. O. Traktuev, S. Merfeld-Clauss, J. Li et al., "A population of multipotent CD34-positive adipose stromal cells share pericyte and mesenchymal surface markers, reside in a periendothelial location, and stabilize endothelial networks," Circulation Research, vol. 102, no. 1, pp. 77-85, 2008.

[21] A. C. W. Zannettino, S. Paton, A. Arthur et al., "Multipotential human adipose-derived stromal stem cells exhibit a perivascular phenotype in vitro and in vivo," Journal of Cellular Physiology, vol. 214, no. 2, pp. 413-421, 2008.

[22] M. Crisan, S. Yap, L. Casteilla et al., "A perivascular origin for mesenchymal stem cells in multiple human organs," Cell Stem Cell, vol. 3, no. 3, pp. 301-313, 2008. 
[23] L. Zimmerlin, V. S. Donnenberg, M. E. Pfeifer et al., "Stromal vascular progenitors in adult human adipose tissue," Cytometry Part A, vol. 9999A, 2010.

[24] F. M. Nielsen, S. E. Riis, J. I. Andersen et al., "Discrete adipose-derived stem cell subpopulations may display differential functionality after in vitro expansion despite convergence to a common phenotype distribution," Stem Cell Research \& Therapy, vol. 7, no. 1, p. 177, 2016.

[25] L. Zimmerlin, V. S. Donnenberg, and A. D. Donnenberg, "Pericytes: a universal adult tissue stem cell?," Cytometry Part A, vol. 81A, no. 1, pp. 12-14, 2012.

[26] M. Crisan, J. Huard, B. Zheng et al., "Purification and culture of human blood vessel-associated progenitor cells," in Current Protocols in Stem Cell Biology, John Wiley \& Sons, Inc., Hoboken, NJ, USA, 2008.

[27] M. Crisan, B. Deasy, M. Gavina et al., "Purification and LongTerm Culture of Multipotent Progenitor Cells Affiliated with the Walls of Human Blood Vessels: Myoendothelial Cells and Pericytes," Methods in Cell Biology, vol. 86, pp. 295-309, 2008.

[28] M. Corselli, C. W. Chen, M. Crisan, L. Lazzari, and B. Péault, "Perivascular ancestors of adult multipotent stem cells," Arteriosclerosis, Thrombosis, and Vascular Biology, vol. 30, no. 6, pp. 1104-1109, 2010.

[29] C. W. Chen, E. Montelatici, M. Crisan et al., "Perivascular multi-lineage progenitor cells in human organs: regenerative units, cytokine sources or both?," Cytokine \& Growth Factor Reviews, vol. 20, no. 5-6, pp. 429-434, 2009.

[30] M. R. Rad, M. Bohloli, M. Akhavan Rahnama, A. Anbarlou, P. Nazeman, and A. Khojasteh, "Impact of tissue harvesting sites on the cellular behaviors of adipose-derived stem cells: implication for bone tissue engineering," Stem Cells International, vol. 2017, Article ID 2156478, 2017.

[31] A. W. James, J. N. Zara, X. Zhang et al., "Perivascular stem cells: a prospectively purified mesenchymal stem cell population for bone tissue engineering," Stem Cells Translational Medicine, vol. 1, no. 6, pp. 510-519, 2012.

[32] M. A. König, D. D. Canepa, D. Cadosch et al., "Direct transplantation of native pericytes from adipose tissue: a new perspective to stimulate healing in critical size bone defects," Cytotherapy, vol. 18, no. 1, pp. 41-52, 2016.

[33] C. G. Chung, A. W. James, G. Asatrian et al., "Human Perivascular Stem Cell-Based Bone Graft Substitute Induces Rat Spinal Fusion," Stem Cells Translational Medicine, vol. 4, no. 5, pp. 538-538, 2015.

[34] T. Tawonsawatruk, C. C. West, I. R. Murray, C. Soo, B. Péault, and A. H. R. W. Simpson, "Adipose derived pericytes rescue fractures from a failure of healing - non- union," Scientific Reports, vol. 6, no. 1, 2016.

[35] C. A. Meyers, J. Casamitjana, L. Chang, L. Zhang, A. W. James, and B. Péault, "Pericytes for therapeutic bone repair," in Advances in Experimental Medicine and Biology, pp. 2132, Springer, Cham, 2018.

[36] Y. Wang, J. Xu, L. Chang et al., "Relative contributions of adipose-resident $\mathrm{CD} 146^{+}$pericytes and $\mathrm{CD} 34^{+}$adventitial progenitor cells in bone tissue engineering," npj Regenerative Medicine, vol. 4, no. 1, 2019.

[37] C. Sobacchi, M. Erreni, D. Strina, E. Palagano, A. Villa, and C. Menale, "3D bone biomimetic scaffolds for basic and translational studies with mesenchymal stem cells," International Journal of Molecular Sciences, vol. 19, no. 10, p. 3150, 2018.
[38] S. Yin, W. Zhang, Z. Zhang, and X. Jiang, "Recent Advances in Scaffold Design and Material for Vascularized Tissue-Engineered Bone Regeneration," Advanced Healthcare Materials, vol. 8, no. 10, p. 1801433, 2019.

[39] H. A. Rather, D. Jhala, and R. Vasita, "Dual functional approaches for osteogenesis coupled angiogenesis in bone issue engineering," Materials Science and Engineering C, vol. 103, p. 109761, 2019.

[40] M. Navarro, A. Michiardi, O. Castaño et al., "Biomaterials in orthopaedics," Journal of the Royal Society Interface, vol. 5, no. 27, pp. 1137-1158, 2008.

[41] L. Polo-Corrales, M. Latorre-Esteves, and J. E. Ramirez-Vick, "Scaffold design for bone regeneration," Journal of Nanoscience and Nanotechnology, vol. 14, no. 1, pp. 15-56, 2014.

[42] Q. L. Loh and C. Choong, "Three-dimensional scaffolds for tissue engineering applications: role of porosity and pore size," Tissue Engineering Part B: Reviews, vol. 19, no. 6, pp. 485-502, 2013.

[43] C. M. Murphy, M. G. Haugh, and F. J. O'Brien, "The effect of mean pore size on cell attachment, proliferation and migration in collagen-glycosaminoglycan scaffolds for bone tissue engineering," Biomaterials, vol. 31, no. 3, pp. 461466, 2010

[44] X. Shi, B. Sitharaman, Q. P. Pham et al., "Fabrication of porous ultra-short single-walled carbon nanotube nanocomposite scaffolds for bone tissue engineering," Biomaterials, vol. 28, no. 28, pp. 4078-4090, 2007.

[45] S. Gómez, M. D. Vlad, J. López, and E. Fernández, "Design and properties of 3D scaffolds for bone tissue engineering," Acta Biomaterialia, vol. 42, pp. 341-350, 2016.

[46] H. H. K. Xu, P. Wang, L. Wang et al., "Calcium phosphate cements for bone engineering and their biological properties," Bone Research, vol. 5, no. 1, 2017.

[47] E. García-Gareta, M. J. Coathup, and G. W. Blunn, “Osteoinduction of bone grafting materials for bone repair and regeneration," Bone, vol. 81, pp. 112-121, 2015.

[48] J. Luo, H. Zhang, J. zhu et al., "3-D mineralized silk fibroin/polycaprolactone composite scaffold modified with polyglutamate conjugated with BMP-2 peptide for bone tissue engineering," Colloids and Surfaces B: Biointerfaces, vol. 163, pp. 369-378, 2018.

[49] C. S. Lee, E. S. Bishop, Z. Dumanian et al., "Bone morphogenetic protein-9-stimulated adipocyte-derived mesenchymal progenitors entrapped in a thermoresponsive nanocomposite scaffold facilitate cranial defect repair," Journal of Craniofacial Surgery, vol. 30, no. 6, pp. 1915-1919, 2019.

[50] R. Z. LeGeros, "Calcium phosphate-based osteoinductive materials," Chemical Reviews, vol. 108, no. 11, pp. $4742-$ 4753, 2008.

[51] H. Yuan, Y. Li, J. De Bruijn, K. De Groot, and X. Zhang, "Tissue responses of calcium phosphate cement: a study in dogs," Biomaterials, vol. 21, no. 12, pp. 1283-1290, 2000.

[52] K. Hu and B. R. Olsen, "The roles of vascular endothelial growth factor in bone repair and regeneration," Bone, vol. 91, pp. 30-38, 2016.

[53] C. J. Percival and J. T. Richtsmeier, "Angiogenesis and intramembranous osteogenesis," Developmental Dynamics, vol. 242, no. 8, pp. 909-922, 2013.

[54] W. S. Khan, F. Rayan, B. S. Dhinsa, and D. Marsh, "An Osteoconductive, Osteoinductive, and Osteogenic Tissue- 
Engineered Product for Trauma and Orthopaedic Surgery: How Far Are We?," Stem Cells International, vol. 2012, 7 pages, 2012.

[55] S. Vériter, W. André, N. Aouassar et al., "Human adiposederived mesenchymal stem cells in cell therapy: safety and feasibility in different "hospital exemption" clinical applications," PLoS One, vol. 10, no. 10, 2015.

[56] E. Ko, K. Alberti, J. S. Lee et al., "Nanostructured tendonderived scaffolds for enhanced bone regeneration by human adipose-derived stem cells," ACS Applied Materials \& Interfaces, vol. 8, no. 35, pp. 22819-22829, 2016.

[57] C. Zhang, M. Li, J. Zhu, F. Luo, and J. Zhao, "Enhanced bone repair induced by human adipose-derived stem cells on osteogenic extracellular matrix ornamented small intestinal submucosa," Regenerative Medicine, vol. 12, no. 5, pp. 541-552, 2017.

[58] J. Liu, P. Zhou, Y. Long, C. Huang, and D. Chen, "Repair of bone defects in rat radii with a composite of allogeneic adipose-derived stem cells and heterogeneous deproteinized bone," Stem Cell Research \& Therapy, vol. 9, no. 1, p. 79, 2018.

[59] J. Guerrero, S. Pigeot, J. Müller, D. J. Schaefer, I. Martin, and A. Scherberich, "Fractionated human adipose tissue as a native biomaterial for the generation of a bone organ by endochondral ossification," Acta Biomaterialia, vol. 77, pp. 142-154, 2018.

[60] J. M. Wagner, N. Conze, G. Lewik et al., "Bone allografts combined with adipose-derived stem cells in an optimized cell/volume ratio showed enhanced osteogenesis and angiogenesis in a murine femur defect model," Journal of Molecular Medicine, vol. 97, no. 10, pp. 1439-1450, 2019.

[61] E. Canciani, C. Dellavia, L. M. Ferreira et al., "Human adipose-derived stem cells on rapid prototyped threedimensional hydroxyapatite/beta-tricalcium phosphate scaffold," Journal of Craniofacial Surgery, vol. 27, no. 3, pp. 727-732, 2016.

[62] E. Farré-Guasch, N. Bravenboer, M. N. Helder, E. A. J. M. Schulten, C. M. ten Bruggenkate, and J. Klein-Nulend, "Blood vessel formation and bone regeneration potential of the stromal vascular fraction seeded on a calcium phosphate scaffold in the human maxillary sinus floor elevation model," Materials, vol. 11, no. 1, p. 161, 2018.

[63] H. Zhang, Y. Zhou, W. Zhang et al., "Construction of vascularized tissue-engineered bone with a double-cell sheet complex," Acta Biomaterialia, vol. 77, pp. 212-227, 2018.

[64] S. Chandran, S. J. Shenoy, S. Suresh Babu, R. P. Nair, H. K. Varma, and A. John, "Strontium hydroxyapatite scaffolds engineered with stem cells aid osteointegration and osteogenesis in osteoporotic sheep model," Colloids and Surfaces B: Biointerfaces, vol. 163, pp. 346-354, 2018.

[65] P. P. Carvalho, I. B. Leonor, B. J. Smith et al., "Undifferentiated human adipose-derived stromal/stem cells loaded onto wet-spun starch-polycaprolactone scaffolds enhance bone regeneration: Nude mice calvarial defect in vivo study," Journal of Biomedical Materials Research Part A, vol. 102, no. 9, pp. 3102-3111, 2014.

[66] L. F. Mellor, M. Mohiti-Asli, J. Williams et al., "Extracellular calcium modulates chondrogenic and osteogenic differentiation of human adipose-derived stem cells: a novel approach for osteochondral tissue engineering using a single stem cell source," Tissue Engineering Part A, vol. 21, no. 17-18, pp. 2323-2333, 2015.
[67] J. W. Lee, S. G. Chu, H. T. Kim et al., "Osteogenesis of adipose-derived and bone marrow stem cells with polycaprolactone/tricalcium phosphate and three-dimensional printing technology in a dog model of maxillary bone defects," Polymers, vol. 9, no. 12, p. 450, 2017.

[68] W. Duan, C. Chen, M. Haque, D. Hayes, and M. J. Lopez, "Polymer-mineral scaffold augments in vivo equine multipotent stromal cell osteogenesis," Stem Cell Research \& Therapy, vol. 9, no. 1, p. 60, 2018.

[69] C. Correia, S. Bhumiratana, L.-P. Yan et al., "Development of silk-based scaffolds for tissue engineering of bone from human adipose-derived stem cells," Acta Biomaterialia, vol. 8, no. 7, pp. 2483-2492, 2012.

[70] G. Calabrese, R. Giuffrida, C. Fabbi et al., "Collagen-hydroxyapatite scaffolds induce human adipose derived stem cells osteogenic differentiation in Vitro," PLoS One, vol. 11, no. 3, p. e0151181, 2016.

[71] E. Mazzoni, A. D’Agostino, M. Manfrini et al., "Human adipose stem cells induced to osteogenic differentiation by an innovative collagen/hydroxylapatite hybrid scaffold," The FASEB Journal, vol. 31, no. 10, pp. 4555-4565, 2017.

[72] S. Toosi, H. Naderi-Meshkin, F. Kalalinia et al., "Bone defect healing is induced by collagen sponge/polyglycolic acid," Journal of Materials Science: Materials in Medicine, vol. 30, 2019.

[73] E. Ko, J. S. Lee, H. Kim et al., "Electrospun silk fibroin nanofibrous scaffolds with two-stage hydroxyapatite functionalization for enhancing the osteogenic differentiation of human adipose-derived mesenchymal stem cells," ACS Applied Materials \& Interfaces, vol. 10, no. 9, pp. 7614-7625, 2018.

[74] A. Porzionato, E. Stocco, S. Barbon, F. Grandi, V. Macchi, and R. De Caro, "Tissue-engineered grafts from human decellularized extracellular matrices: a systematic review and future perspectives," International Journal of Molecular Sciences, vol. 19, no. 12, p. 4117, 2018.

[75] R. A. Thibault, A. G. Mikos, and F. K. Kasper, "Scaffold/Extracellular Matrix Hybrid Constructs for Bone-Tissue Engineering," Advanced Healthcare Materials, vol. 2, no. 1, pp. 13-24, 2013.

[76] C. B. Thomas, S. Maxson, and K. J. L. Burg, "Preparation and characterization of a composite of demineralized bone matrix fragments and polylactide beads for bone tissue engineering," Journal of Biomaterials Science, Polymer Edition, vol. 22, no. 4-6, pp. 589-610, 2011.

[77] P. Y. Ni, M. Fan, Z. Y. Qian et al., "Synthesis and characterization of injectable, thermosensitive, and biocompatible acellular bone matrix/poly(ethylene glycol)-poly ( $\varepsilon$-caprolactone)-poly(ethylene glycol) hydrogel composite," Journal of Biomedical Materials Research Part A, vol. 100A, no. 1, pp. 171-179, 2012.

[78] R. da Silva, V. Crivellaro, A. Giovanini, R. Scariot, C. Gonzaga, and J. Zielak, "Radiographic and histological evaluation of ectopic application of deproteinized bovine bone matrix," Annals of Maxillofacial Surgery, vol. 6, 2016.

[79] S. Samavedi, A. R. Whittington, and A. S. Goldstein, "Calcium phosphate ceramics in bone tissue engineering: a review of properties and their influence on cell behavior," Acta Biomaterialia, vol. 9, no. 9, pp. 8037-8045, 2013.

[80] Z. Tang, X. Li, Y. Tan, H. Fan, and X. Zhang, “The material and biological characteristics of osteoinductive calcium 
phosphate ceramics," Regenerative Biomaterials, vol. 5, no. 1, pp. 43-59, 2018.

[81] L. Cheng, F. Ye, R. Yang et al., "Osteoinduction of hydroxyapatite/ $\beta$-tricalcium phosphate bioceramics in mice with a fractured fibula," Acta Biomaterialia, vol. 6, no. 4, pp. 15691574, 2010.

[82] M. Neral, M. Solari, C. Purnell, and R. Wollstein, "The use of bone cement in difficult distal radius fractures," Hand, vol. 8, no. 4, pp. 387-391, 2013.

[83] P. Kopylov, K. Jonsson, K. G. Thorngren, and P. Aspenberg, "Injectable calcium phosphate in the treatment of distal radial fractures," Journal of Hand Surgery, vol. 21, no. 6, pp. 768771, 1996.

[84] K. Rezwan, Q. Z. Chen, J. J. Blaker, and A. R. Boccaccini, "Biodegradable and bioactive porous polymer/inorganic composite scaffolds for bone tissue engineering," Biomaterials, vol. 27, no. 18, pp. 3413-3431, 2006.

[85] S. Cai, G. H. Xu, X. Z. Yu, W. J. Zhang, Z. Y. Xiao, and K. D. Yao, "Fabrication and biological characteristics of $\beta$-tricalcium phosphate porous ceramic scaffolds reinforced with calcium phosphate glass," Journal of Materials Science: Materials in Medicine, vol. 20, no. 1, pp. 351-358, 2009.

[86] I. Denry and L. T. Kuhn, "Design and characterization of calcium phosphate ceramic scaffolds for bone tissue engineering," Dental Materials, vol. 32, no. 1, pp. 43-53, 2016.

[87] G. Fernandez de Grado, L. Keller, Y. Idoux-Gillet et al., "Bone substitutes: a review of their characteristics, clinical use, and perspectives for large bone defects management," Journal of Tissue Engineering, vol. 9, 2018.

[88] S. D. McCullen, J. Zhan, M. L. Onorato, S. H. Bernacki, and E. G. Loboa, "Effect of varied ionic calcium on human adipose-derived stem cell mineralization," Tissue Engineering Part A, vol. 16, no. 6, pp. 1971-1981, 2010.

[89] T. Thesleff, K. Lehtimäki, T. Niskakangas et al., "Cranioplasty with adipose-derived stem cells and biomaterial: a novel method for cranial reconstruction," Neurosurgery, vol. 68, no. 6, pp. 1535-1540, 2011.

[90] G. B. Sándor, “Tissue engineering of bone: clinical observations with adipose-derived stem cells, resorbable scaffolds, and growth factors," Annals of Maxillofacial Surgery, vol. 2, no. 1, pp. 8-11, 2012.

[91] G. Sándor, V. Tuovinen, J. Wolff et al., "GMP-level adipose stem cells combined with computer-aided manufacturing to reconstruct mandibular ameloblastoma resection defects: experience with three cases," Annals of Maxillofacial Surgery, vol. 3, no. 2, pp. 114-125, 2013.

[92] V. Offermanns, O. Z. Andersen, G. Riede et al., "Bone regenerating effect of surface-functionalized titanium implants with sustained-release characteristics of strontium in ovariectomized rats," International Journal of Nanomedicine, vol. 11, pp. 2431-2442, 2016.

[93] B. P. Nair, M. Sindhu, and P. D. Nair, "Polycaprolactonelaponite composite scaffold releasing strontium ranelate for bone tissue engineering applications," Colloids and Surfaces B: Biointerfaces, vol. 143, pp. 423-430, 2016.

[94] S. Chandran, S. Suresh Babu, V. S. Hari Krishnan, H. K. Varma, and A. John, "Osteogenic efficacy of strontium hydroxyapatite micro-granules in osteoporotic rat model," Journal of Biomaterials Applications, vol. 31, no. 4, pp. 499509, 2016.
[95] F. Rossi, M. Santoro, and G. Perale, "Polymeric scaffolds as stem cell carriers in bone repair," Journal of Tissue Engineering and Regenerative Medicine, vol. 9, no. 10, pp. 1093-1119, 2015.

[96] B. H. Park, L. Zhou, K. Y. Jang et al., "Enhancement of tibial regeneration in a rat model by adipose-derived stromal cells in a PLGA scaffold," Bone, vol. 51, no. 3, pp. 313-323, 2012.

[97] B. Levi, A. W. James, E. R. Nelson et al., "Human adipose derived stromal cells heal critical size mouse calvarial defects," PLoS One, vol. 5, no. 6, p. e11177, 2010.

[98] V. Campana, G. Milano, E. Pagano et al., "Bone substitutes in orthopaedic surgery: from basic science to clinical practice," Journal of Materials Science: Materials in Medicine, vol. 25, no. 10, pp. 2445-2461, 2014.

[99] R. Xue, Y. Qian, L. Li, G. Yao, L. Yang, and Y. Sun, "Polycaprolactone nanofiber scaffold enhances the osteogenic differentiation potency of various human tissue-derived mesenchymal stem cells," Stem Cell Research \& Therapy, vol. 8, no. 1, p. 148, 2017.

[100] A. S. Zanetti, C. Sabliov, J. M. Gimble, and D. J. Hayes, "Human adipose-derived stem cells and three-dimensional scaffold constructs: A review of the biomaterials and models currently used for bone regeneration," Journal of Biomedical Materials Research Part B: Applied Biomaterials, vol. 101, pp. 187-199, 2013.

[101] D. Wu, X. Chen, T. Chen, C. Ding, W. Wu, and J. Li, "Substrate-anchored and degradation-sensitive antiinflammatory coatings for implant materials," Scientific Reports, vol. 5, 2015.

[102] R. Shi, Y. Huang, C. Ma, C. Wu, and W. Tian, "Current advances for bone regeneration based on tissue engineering strategies," Frontiers of Medicine, vol. 13, no. 2, pp. 160$188,2019$.

[103] T. M. Myckatyn, I. J. Wagner, B. J. Mehrara et al., "Cancer risk after fat transfer: a multicenter case-cohort study," Plastic and Reconstructive Surgery, vol. 139, no. 1, pp. 11-18, 2017.

[104] B. S. Kim, S. S. Yang, and C. S. Kim, "Incorporation of BMP-2 nanoparticles on the surface of a 3D-printed hydroxyapatite scaffold using an $\varepsilon$-polycaprolactone polymer emulsion coating method for bone tissue engineering," Colloids and Surfaces B: Biointerfaces, vol. 170, pp. 421-429, 2018.

[105] L. Keller, S. Eap, J. Schiavi et al., "A living thick nanofibrous implant bifunctionalized with active growth factor and stem cells for bone regeneration," International Journal of Nanomedicine, vol. 10, pp. 1061-1075, 2015.

[106] S. A. Sell, P. S. Wolfe, K. Garg, J. M. McCool, I. A. Rodriguez, and G. L. Bowlin, "The use of natural polymers in tissue engineering: a focus on electrospun extracellular matrix analogues," Polymers, vol. 2, no. 4, pp. 522-553, 2010.

[107] W. J. Jurgens, R. J. Kroeze, R. A. Bank, M. J. P. F. Ritt, and M. N. Helder, "Rapid attachment of adipose stromal cells on resorbable polymeric scaffolds facilitates the one-step surgical procedure for cartilage and bone tissue engineering purposes," Journal of Orthopaedic Research, vol. 29, no. 6, pp. 853-860, 2011.

[108] Institute for Surgical Research and Hospital Management, A. M. Müller, A. Mehrkens et al., "Towards an intraoperative engineering of osteogenic and vasculogenic grafts from the stromal vascular fraction of human adipose tissue," European Cells and Materials, vol. 19, pp. 127-135, 2010. 
[109] S. Güven, A. Mehrkens, F. Saxer et al., "Engineering of large osteogenic grafts with rapid engraftment capacity using mesenchymal and endothelial progenitors from human adipose tissue," Biomaterials, vol. 32, no. 25, pp. 5801-5809, 2011.

[110] D. T. Leong, W. K. Nah, A. Gupta, D. W. Hutmacher, and M. A. Woodruff, "The osteogenic differentiation of adipose tissue-derived precursor cells in a 3D scaffold/matrix environment," Current Drug Discovery Technologies, vol. 5, no. 4, pp. 319-327, 2008.

[111] C. Weinand, A. Nabili, M. Khumar et al., "Factors of osteogenesis influencing various human stem cells on thirdgeneration gelatin/ $\beta$-tricalcium phosphate scaffold material," Rejuvenation Research, vol. 14, no. 2, pp. 185-194, 2011.

[112] S. Afewerki, A. Sheikhi, S. Kannan, S. Ahadian, and A. Khademhosseini, "Gelatin-polysaccharide composite scaffolds for 3D cell culture and tissue engineering: Towards natural therapeutics," Bioengineering \& Translational Medicine, vol. 4, no. 1, pp. 96-115, 2019.

[113] F. Khan and S. R. Ahmad, "Polysaccharides and their derivatives for versatile tissue engineering application," Macromolecular Bioscience, vol. 13, no. 4, pp. 395-421, 2013.

[114] M. Rodríguez-Vázquez, B. Vega-Ruiz, R. Ramos-Zúñiga, D. A. Saldaña-Koppel, and L. F. Quiñones-Olvera, "Chitosan and its potential use as a scaffold for tissue engineering in regenerative medicine," BioMed Research International, vol. 2015, 15 pages, 2015.

[115] J. F. Requicha, C. A. Viegas, S. Hede, I. B. Leonor, R. L. Reis, and M. E. Gomes, "Design and characterization of a biodegradable double-layer scaffold aimed at periodontal tissue-engineering applications," Journal of Tissue Engineering and Regenerative Medicine, vol. 10, no. 5, pp. 392-403, 2016.

[116] D. Mehrabani, A. Khodakaram-Tafti, H. Shaterzadeh-Yazdi, B. Zamiri, and M. Omidi, "Comparison of the regenerative effect of adipose-derived stem cells, fibrin glue scaffold, and autologous bone graft in experimental mandibular defect in rabbit," Dental Traumatology, vol. 34, no. 6, pp. 413-420, 2018.

[117] J. Xie, M. Bao, S. M. C. Bruekers, and W. T. S. Huck, "Collagen gels with different fibrillar microarchitectures elicit different cellular responses," ACS Applied Materials \& Interfaces, vol. 9, no. 23, pp. 19630-19637, 2017.

[118] N. Kakudo, A. Shimotsuma, S. Miyake, S. Kushida, and K. Kusumoto, "Bone tissue engineering using human adipose-derived stem cells and honeycomb collagen scaffold," Journal of Biomedical Materials Research Part A, vol. 84A, no. 1, pp. 191-197, 2008.

[119] A. Corsetti, C. Bahuschewskyj, D. Ponzoni et al., "Repair of bone defects using adipose-derived stem cells combined with alpha-tricalcium phosphate and gelatin sponge scaffolds in a rat model," Journal of Applied Oral Science, vol. 25, no. 1, pp. 10-19, 2017.

[120] X. Wang, T. Yu, G. Chen, J. Zou, J. Li, and J. Yan, "Preparation and characterization of a chitosan/gelatin/extracellular matrix scaffold and its application in tissue engineering," Tissue Engineering Part C: Methods, vol. 23, no. 3, pp. 169-179, 2017.

[121] Z. H. Wang, Y. F. Tian, H. Zhang et al., "Using hyaluronic acid-functionalized $\mathrm{pH}$ stimuli-responsive mesoporous silica nanoparticles for targeted delivery to CD44-overexpressing cancer cells," International Journal of Nanomedicine, vol. Volume 11, pp. 6485-6497, 2016.
[122] X. Ding, M. Zhu, B. Xu et al., "Integrated trilayered silk fibroin scaffold for osteochondral differentiation of adiposederived stem cells," ACS Applied Materials \& Interfaces, vol. 6, no. 19, pp. 16696-16705, 2014.

[123] G. Turnbull, J. Clarke, F. Picard et al., "3D bioactive composite scaffolds for bone tissue engineering," Bioactive Materials, vol. 3, no. 3, pp. 278-314, 2018.

[124] D. Zhang, X. Wu, J. Chen, and K. Lin, "The development of collagen based composite scaffolds for bone regeneration," Bioactive Materials, vol. 3, no. 1, pp. 129-138, 2018.

[125] A. Lode, M. Meyer, S. Brüggemeier et al., "Additive manufacturing of collagen scaffolds by three-dimensional plotting of highly viscous dispersions," Biofabrication, vol. 8, no. 1, 2016.

[126] S. H. Kim, Y. K. Yeon, J. M. Lee et al., "Precisely printable and biocompatible silk fibroin bioink for digital light processing 3D printing," Nature Communications, vol. 9, no. 1, 2018.

[127] Y.-W. Chen, Y.-F. Shen, C.-C. Ho et al., "Osteogenic and angiogenic potentials of the cell-laden hydrogel/musselinspired calcium silicate complex hierarchical porous scaffold fabricated by 3D bioprinting," Materials Science and Engineering: $C$, vol. 91, pp. 679-687, 2018.

[128] Z. Zheng, J. Wu, M. Liu et al., “3D Bioprinting of Self-Standing Silk-Based Bioink," Advanced Healthcare Materials, vol. 7, no. 6, p. 1701026, 2018.

[129] T. T. Demirtaş, G. Irmak, and M. Gümüşderelioğlu, “A bioprintable form of chitosan hydrogel for bone tissue engineering," Biofabrication, vol. 9, no. 3, p. 035003, 2017.

[130] W. Duan, M. Haque, M. T. Kearney, and M. J. Lopez, "Collagen and hydroxyapatite scaffolds activate distinct osteogenesis signaling pathways in adult adipose-derived multipotent stromal cells," Tissue Engineering Part C: Methods, vol. 23, no. 10, pp. 592-603, 2017.

[131] A. D’Agostino, L. Trevisiol, V. Favero et al., "Hydroxyapatite/collagen composite is a reliable material for malar augmentation," Journal of Oral and Maxillofacial Surgery, vol. 74, 2016.

[132] M. G. Scioli, A. Bielli, P. Gentile, V. Cervelli, and A. Orlandi, "Combined treatment with platelet-rich plasma and insulin favours chondrogenic and osteogenic differentiation of human adipose-derived stem cells in three-dimensional collagen scaffolds," Journal of Tissue Engineering and Regenerative Medicine, vol. 11, no. 8, pp. 2398-2410, 2017.

[133] W. M. Hodges, F. O’Brien, S. Fulzele, and M. W. Hamrick, "Function of microRNAs in the osteogenic differentiation and therapeutic application of adipose-derived stem cells (ASCs)," International Journal of Molecular Sciences, vol. 18, no. 12, p. 2597, 2017.

[134] E. C. Martin, A. T. Qureshi, V. Dasa, M. A. Freitas, J. M. Gimble, and T. A. Davis, "MicroRNA regulation of stem cell differentiation and diseases of the bone and adipose tissue: perspectives on miRNA biogenesis and cellular transcriptome," Biochimie, vol. 124, pp. 98-111, 2016.

[135] H. Yoshioka and Y. Yoshiko, "The roles of long non-proteincoding RNAs in osteo-adipogenic lineage commitment," International Journal of Molecular Sciences, vol. 18, no. 6, p. 1236, 2017.

[136] Q. Yang, L. Jia, X. Li et al., "Long noncoding RNAs: new players in the osteogenic differentiation of bone marrowand adipose-derived mesenchymal stem cells," Stem Cell Reviews and Reports, vol. 14, no. 3, pp. 297-308, 2018. 
[137] G. Caetano, W. Wang, A. Murashima et al., "Tissue constructs with human adipose-derived mesenchymal stem cells to treat bone defects in rats," Materials, vol. 12, no. 14, p. 2268, 2019.

[138] M. Madrigal, K. S. Rao, and N. H. Riordan, "A review of therapeutic effects of mesenchymal stem cell secretions and induction of secretory modification by different culture methods," Journal of Translational Medicine, vol. 12, no. 1, p. 260, 2014.

[139] P. Hong, H. Yang, Y. Wu, K. Li, and Z. Tang, "The functions and clinical application potential of exosomes derived from adipose mesenchymal stem cells: a comprehensive review," Stem Cell Research \& Therapy, vol. 10, no. 1, p. 242, 2019.

[140] W. Li, Y. Liu, P. Zhang et al., "Tissue-engineered bone immobilized with human adipose stem cells-derived exosomes promotes bone regeneration," ACS Applied Materials \& Interfaces, vol. 10, no. 6, pp. 5240-5254, 2018.

[141] L. Hu, J. Wang, X. Zhou et al., "Exosomes derived from human adipose mensenchymal stem cells accelerates cutaneous wound healing via optimizing the characteristics of fibroblasts," Scientific Reports, vol. 6, no. 1, 2016.

[142] S. Kaur, S. P. Singh, A. G. Elkahloun, W. Wu, M. S. AbuAsab, and D. D. Roberts, "CD47-dependent immunomodulatory and angiogenic activities of extracellular vesicles produced by T cells," Matrix Biology, vol. 37, pp. 49-59, 2014.

[143] C. Sobacchi, E. Palagano, A. Villa, and C. Menale, "Soluble factors on stage to direct mesenchymal stem cells fate," Frontiers in Bioengineering and Biotechnology, vol. 5, pp. 1-9, 2017.

[144] M. Mohammadi, M. Alibolandi, K. Abnous, Z. Salmasi, M. R. Jaafari, and M. Ramezani, "Fabrication of hybrid scaffold based on hydroxyapatite-biodegradable nanofibers incorporated with liposomal formulation of BMP-2 peptide for bone tissue engineering," Nanomedicine: Nanotechnology, Biology and Medicine, vol. 14, no. 7, pp. 1987-1997, 2018.

[145] S. L. Moradi, A. Golchin, Z. Hajishafieeha, M. M. Khani, and A. Ardeshirylajimi, "Bone tissue engineering: adult stem cells in combination with electrospun nanofibrous scaffolds," Journal of Cellular Physiology, vol. 233, no. 10, pp. 65096522, 2018.

[146] M. A. Arriaga, M.-. H. Ding, A. S. Gutierrez, and S. A. Chew, "The Application of microRNAs in Biomaterial ScaffoldBased Therapies for Bone Tissue Engineering," Biotechnology Journal, vol. 14, no. 10, p. 1900084, 2019.

[147] A. Das, D. A. Barker, T. Wang, C. M. Lau, Y. Lin, and E. A. Botchwey, "Delivery of bioactive lipids from composite microgel-microsphere injectable scaffolds enhances stem cell recruitment and skeletal repair," PLoS One, vol. 9, no. 7, 2014.

[148] W.-L. Yu, T.-W. Sun, C. Qi et al., "Enhanced osteogenesis and angiogenesis by mesoporous hydroxyapatite microspheresderived simvastatin sustained release system for superior bone regeneration," Scientific Reports, vol. 7, 2017.

[149] H. X. Zhang, X. P. Zhang, G. Y. Xiao et al., "In vitro and in vivo evaluation of calcium phosphate composite scaffolds containing BMP-VEGF loaded PLGA microspheres for the treatment of avascular necrosis of the femoral head," Materials Science and Engineering: C, vol. 60, pp. 298-307, 2016.

[150] B. Li, H. Wang, G. Qiu, X. Su, and Z. Wu, "Synergistic effects of vascular endothelial growth factor on bone morphogenetic proteins induced bone formation in vivo: influencing factors and future research directions," BioMed Research International, vol. 2016, Article ID 2869572, 11 pages, 2016.
[151] K. Mesimäki, B. Lindroos, J. Törnwall et al., "Novel maxillary reconstruction with ectopic bone formation by GMP adipose stem cells," International Journal of Oral and Maxillofacial Surgery, vol. 38, no. 3, pp. 201-209, 2009.

[152] G. K. Sándor, J. Numminen, J. Wolff et al., “Adipose Stem Cells Used to Reconstruct 13 Cases With Cranio-Maxillofacial Hard-Tissue Defects," Stem Cells Translational Medicine, vol. 3, no. 4, pp. 530-540, 2014.

[153] L. Mazzucco, V. Balbo, E. Cattana, R. Guaschino, and P. Borzini, "Not every PRP-gel is born equal Evaluation of growth factor availability for tissues through four PRP-gel preparations: Fibrinet ${ }^{\circledR}$, RegenPRP-Kit ${ }^{\circledR}$, Plateltex ${ }^{\circledR}$ and one manual procedure," Vox Sanguinis, vol. 97, no. 2, pp. 110118, 2009.

[154] S. J. Najman, V. J. Cvetković, J. G. Najdanović et al., “Ectopic osteogenic capacity of freshly isolated adipose-derived stromal vascular fraction cells supported with platelet-rich plasma: a simulation of intraoperative procedure," Journal of Cranio-Maxillofacial Surgery, vol. 44, no. 10, pp. 17501760, 2016.

[155] H. Liao, M.-J. Tsai, M. Brahmayya, and J.-P. Chen, "Bone regeneration using adipose-derived stem cells in injectable thermo-gelling hydrogel scaffold containing platelet-rich plasma and biphasic calcium phosphate," International Journal of Molecular Sciences, vol. 19, no. 9, p. 2537, 2018.

[156] M. S. Kashef-Saberi, N. Hayati Roodbari, K. Parivar, S. Vakilian, and H. Hanaee-Ahvaz, "Enhanced osteogenic differentiation of mesenchymal stem cells on electrospun polyethersulfone/poly(vinyl) alcohol/platelet rich plasma nanofibrous scaffolds," ASAIO Journal, vol. 64, no. 5, pp. e115-e122, 2018.

[157] M. Kazem-Arki, M. Kabiri, I. Rad et al., "Enhancement of osteogenic differentiation of adipose-derived stem cells by PRP modified nanofibrous scaffold," Cytotechnology, vol. 70, no. 6, pp. 1487-1498, 2018.

[158] S. Bayraktar, P. Jungbluth, R. Deenen et al., "Molecularand microarray-based analysis of diversity among resting and osteogenically induced porcine mesenchymal stromal cells of several tissue origin," Journal of Tissue Engineering and Regenerative Medicine, vol. 12, no. 1, pp. 114-128, 2018.

[159] M. Marędziak, K. Marycz, D. Lewandowski, A. Siudzińska, and A. Śmieszek, "Static magnetic field enhances synthesis and secretion of membrane-derived microvesicles (MVs) rich in VEGF and BMP-2 in equine adipose-derived stromal cells (EqASCs) - a new approach in veterinary regenerative medicine," In Vitro Cellular \& Developmental Biology - Animal, vol. 51, no. 3, pp. 230-240, 2015.

[160] L. Biancone, S. Bruno, M. C. Deregibus, C. Tetta, and G. Camussi, "Therapeutic potential of mesenchymal stem cell-derived microvesicles," Nephrology Dialysis Transplantation, vol. 27, no. 8, pp. 3037-3042, 2012.

[161] C. Y. Lin, Y. H. Chang, K. C. Li et al., "The use of ASCs engineered to express BMP2 or TGF- $\beta 3$ within scaffold constructs to promote calvarial bone repair," Biomaterials, vol. 34, no. 37, pp. 9401-9412, 2013.

[162] M. Tkach and C. Théry, "Communication by extracellular vesicles: where we are and where we need to go," Cell, vol. 164, no. 6, pp. 1226-1232, 2016.

[163] G. Raposo and W. Stoorvogel, "Extracellular vesicles: exosomes, microvesicles, and friends," The Journal of Cell Biology, vol. 200, no. 4, pp. 373-383, 2013. 
[164] D. Koppers-Lalic, M. M. Hogenboom, J. M. Middeldorp, and D. M. Pegtel, "Virus-modified exosomes for targeted RNA delivery; A new approach in nanomedicine," Advanced Drug Delivery Reviews, vol. 65, no. 3, pp. 348-356, 2013.

[165] S. Zhang, W. C. Chu, R. C. Lai, S. K. Lim, J. H. P. Hui, and W. S. Toh, "Exosomes derived from human embryonic mesenchymal stem cells promote osteochondral regeneration," Osteoarthritis and Cartilage, vol. 24, no. 12, pp. 2135-2140, 2016.

[166] K. Nong, W. Wang, X. Niu et al., "Hepatoprotective effect of exosomes from human-induced pluripotent stem cellderived mesenchymal stromal cells against hepatic ischemia-reperfusion injury in rats," Cytotherapy, vol. 18, no. 12, pp. 1548-1559, 2016.

[167] M. Martins, D. Ribeiro, A. Martins, R. L. Reis, and N. M. Neves, "Extracellular vesicles derived from osteogenically induced human bone marrow mesenchymal stem cells can modulate lineage commitment," Stem Cell Reports, vol. 6, no. 3, pp. 284-291, 2016.

[168] Y. Qin, L. Wang, Z. Gao, G. Chen, and C. Zhang, "Bone marrow stromal/stem cell-derived extracellular vesicles regulate osteoblast activity and differentiation in vitro and promote bone regeneration in vivo," Scientific Reports, vol. 6, no. 21961, 2016.

[169] Z. Lu, Y. Chen, C. Dunstan, S. Roohani-Esfahani, and H. Zreiqat, "Priming adipose stem cells with tumor necrosis factor-alpha preconditioning potentiates their exosome efficacy for bone regeneration," Tissue Engineering Part A, vol. 23, no. 21-22, pp. 1212-1220, 2017.

[170] Z. Yuan, Q. Li, S. Luo et al., "PPAR $\gamma$; and Wnt signaling in adipogenic and osteogenic differentiation of mesenchymal stem cells," Current Stem Cell Research \& Therapy, vol. 11, no. 3, pp. 216-225, 2016.

[171] Y. Zhu, Y. Wang, Y. Jia, J. Xu, and Y. Chai, "Catalpol promotes the osteogenic differentiation of bone marrow mesenchymal stem cells via the Wnt/ $\beta$-catenin pathway," Stem Cell Research \& Therapy, vol. 10, no. 1, p. 37, 2019.

[172] S. Yang, S. Guo, S. Tong, and X. Sun, "Promoting osteogenic differentiation of human adipose-derived stem cells by altering the expression of exosomal miRNA," Stem Cells International, vol. 2019, Article ID 1351860, 15 pages, 2019.

[173] K. Seenprachawong, T. Tawornsawutruk, C. Nantasenamat, P. Nuchnoi, S. Hongeng, and A. Supokawej, "miR-130a and miR-27b enhance osteogenesis in human bone marrow mesenchymal stem cells via specific down-regulation of peroxisome proliferator-activated receptor $\gamma$," Frontiers in Genetics, vol. 9, 2018.

[174] E. E. M. Chen, W. Zhang, C. C. Y. Ye et al., "Knockdown of SIRT7 enhances the osteogenic differentiation of human bone marrow mesenchymal stem cells partly via activation of the Wnt/ $\beta$-catenin signaling pathway," Cell Death \& Disease, vol. 8, no. 9, p. e3042, 2017.

[175] Q. Xie, W. Wei, J. Ruan et al., "Effects of miR-146a on the osteogenesis of adipose-derived mesenchymal stem cells and bone regeneration," Scientific Reports, vol. 7, 2017.

[176] Q. Xie, Z. Wang, H. Zhou et al., "The role of miR-135modified adipose-derived mesenchymal stem cells in bone regeneration," Biomaterials, vol. 75, pp. 279-294, 2016.
[177] Y. H. Liao, Y. H. Chang, L. Y. Sung et al., "Osteogenic differentiation of adipose-derived stem cells and calvarial defect repair using baculovirus-mediated co-expression of BMP-2 and miR-148b," Biomaterials, vol. 35 , no. 18, pp. 49014910, 2014.

[178] A. T. Qureshi, A. Doyle, C. Chen et al., "Photoactivated miR148b-nanoparticle conjugates improve closure of critical size mouse calvarial defects," Acta Biomaterialia, vol. 12, pp. 166$173,2015$.

[179] K. C. Li, S. C. Lo, L. Y. Sung, Y. H. Liao, Y. H. Chang, and Y. C. Hu, "Improved calvarial bone repair by hASCs engineered with Cre/loxP-based baculovirus conferring prolonged BMP-2 and MiR-148b co-expression," Journal of Tissue Engineering and Regenerative Medicine, vol. 11, no. 11, pp. 3068-3077, 2017.

[180] Z. Wang, D. Zhang, Z. Hu et al., "MicroRNA-26a-modified adipose-derived stem cells incorporated with a porous hydroxyapatite scaffold improve the repair of bone defects," Molecular Medicine Reports, vol. 12, no. 3, pp. 3345-3350, 2015.

[181] Y. Deng, H. Zhou, D. Zou et al., "The role of miR-31modified adipose tissue-derived stem cells in repairing rat critical-sized calvarial defects," Biomaterials, vol. 34 , no. 28 , pp. 6717-6728, 2013. 


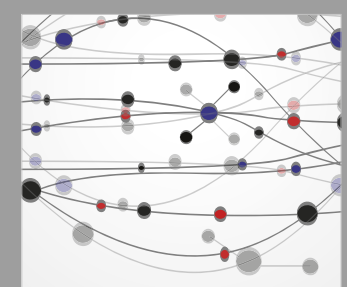

The Scientific World Journal
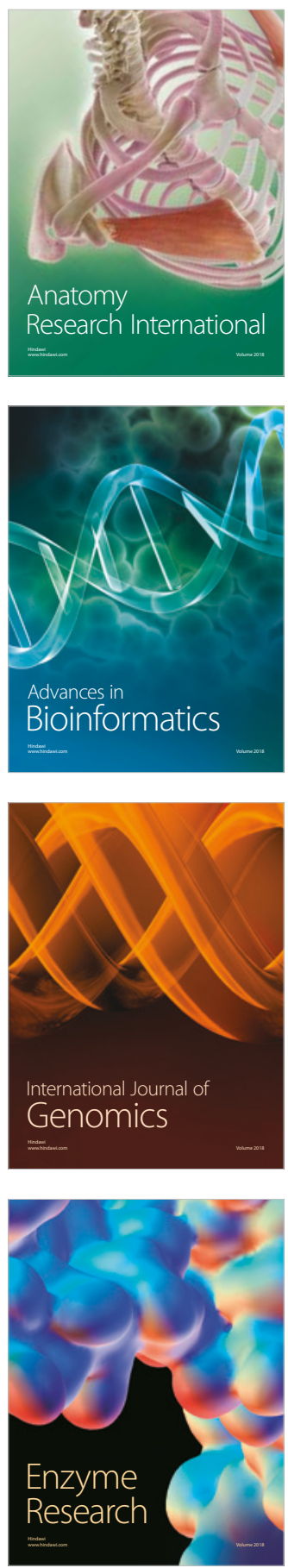
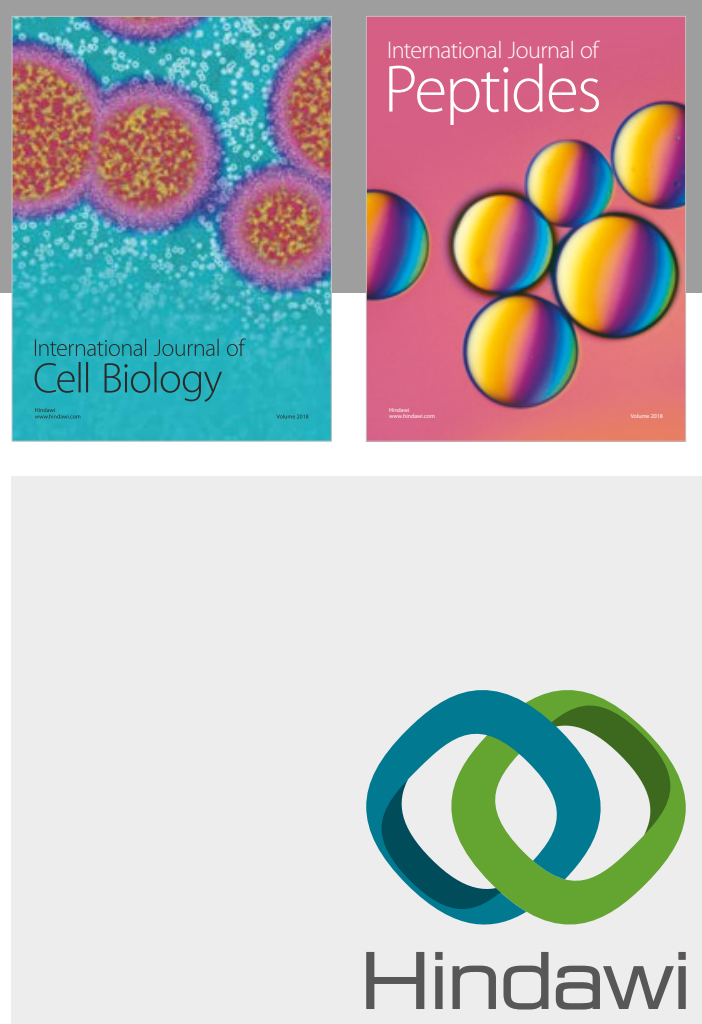

Submit your manuscripts at

www.hindawi.com
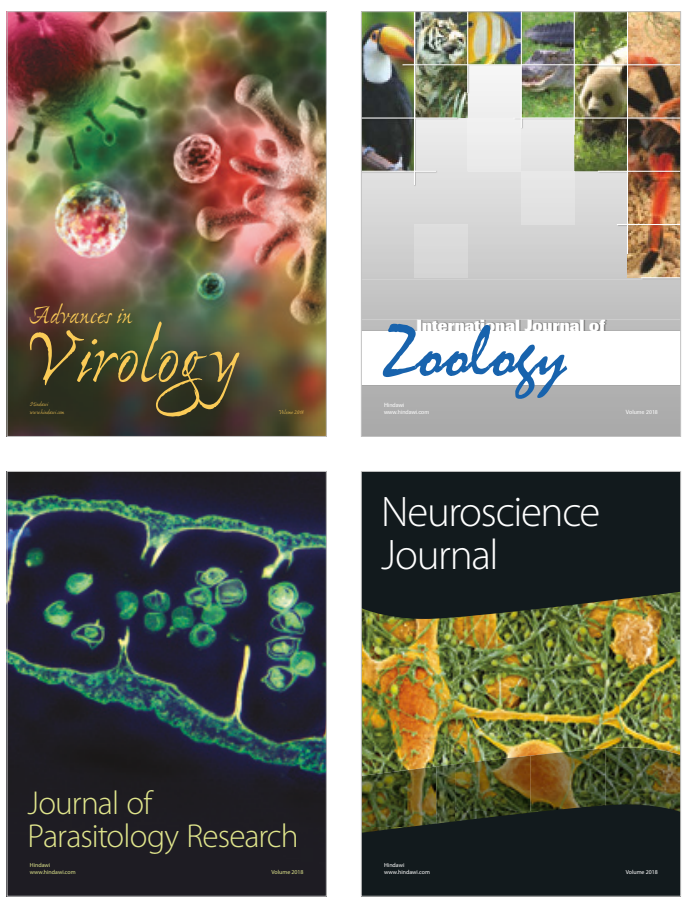
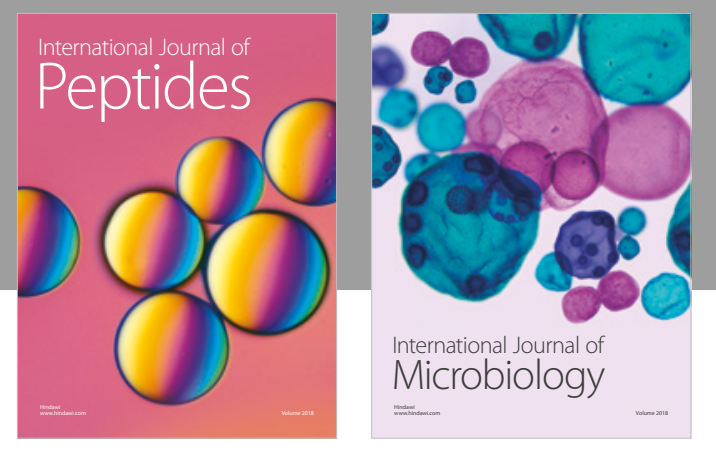

nternational Journal of Microbiology
Journal of
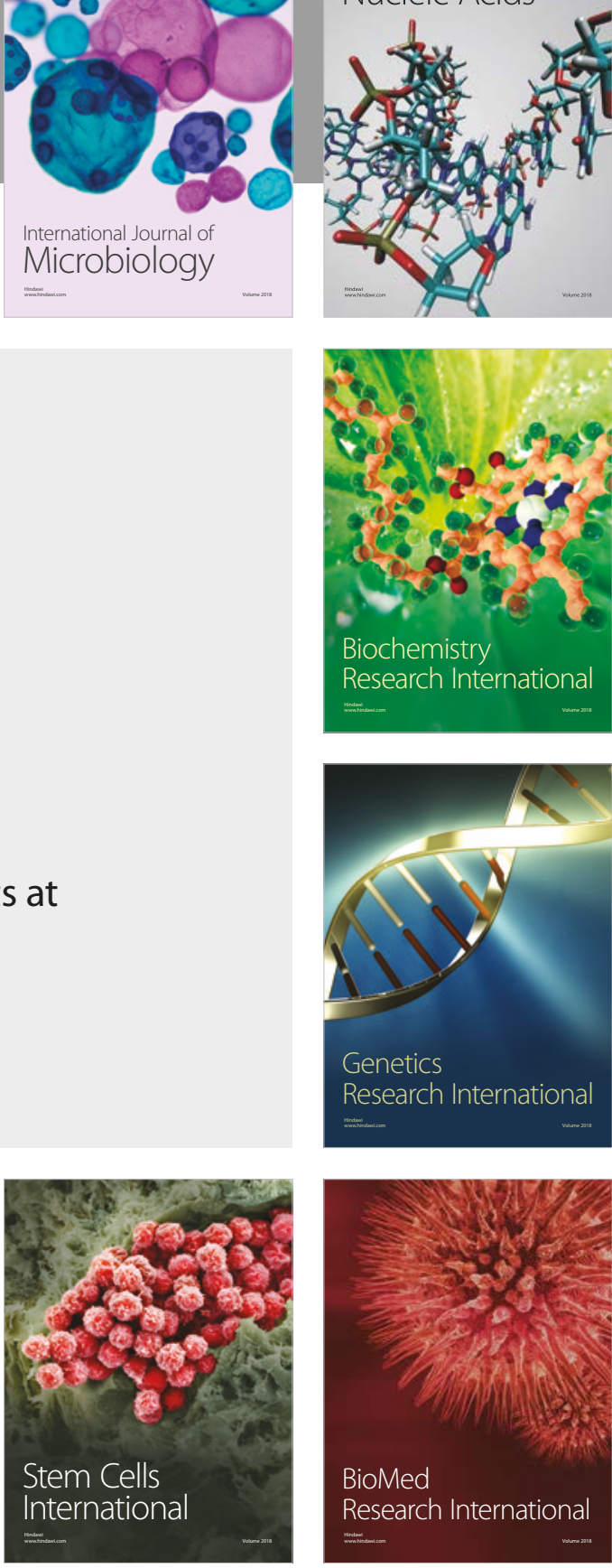
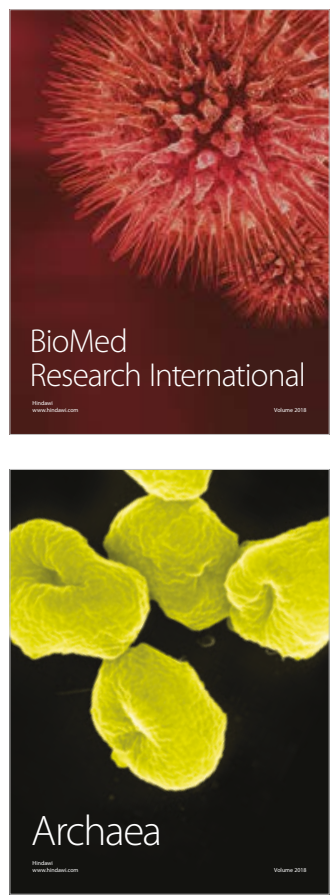